\title{
Ab Initio Molecular Orbital Calculation for Optical and Electronic Properties Evaluation of Small and Medium Size Silicon Nano-Clusters Found in Silicon Rich Oxide Films
}

\author{
Néstor David Espinosa Torres ${ }^{1}$, José Francisco Javier Flores Gracia ${ }^{1}$, José Alberto Luna López ${ }^{1}$, \\ Juan Carlos Ramírez García ${ }^{2}$, Alfredo Morales Sánchez ${ }^{3}$, José Luis Sosa Sánchez ${ }^{1}$, \\ David Hernández de la Luz ${ }^{1}$, Francisco Morales Morales ${ }^{1}$ \\ ${ }^{1}$ Research Center for Semiconductor Devices, CIDS-ICUAP-BUAP, Puebla, México \\ ${ }^{2}$ The Faculty of Chemical Sciences, BUAP, Puebla, México \\ ${ }^{3}$ Research Center for Advanced Materials S.C. Unit Monterrey-PIIT, Apodaca, México \\ Email: *siox130@gmail.com
}

Received August 2, 2013; revised September 5, 2013; accepted October 3, 2013

Copyright (C) 2013 Néstor David Espinosa Torres et al. This is an open access article distributed under the Creative Commons Attribution License, which permits unrestricted use, distribution, and reproduction in any medium, provided the original work is properly cited.

\begin{abstract}
In systems in atomic and nano scales such as clusters or agglomerates constituted of particles from a few to less than one hundred of atoms, quantum confinement effects are very important. Their optical and electronic properties are often dependent on the size of the systems and the way in which the atoms in these clusters are bonded. Generally, these nano-structures display optical and electronic properties significantly different of those found in corresponding bulk materials. Silicon agglomerates found in Silicon Rich Oxide (SRO) films have optical properties, which have reported as depended directly on nano-crystal size. Furthermore, the room temperature photoluminescence (PL) of Silicon Rich Oxides (SRO) has repeatedly generated a huge interest due to their possible applications in optoelectronic devices. However, a plausible emission mechanism has not yet widespread acceptance of the scientific community. In this research, we employed the Density Functional Theory with a functional B3LYP and a basis set $6-31 \mathrm{G}^{*}$ to calculate the optical and electronic properties of small (six to ten silicon atoms) and medium size clusters of silicon (constituted of eleven to fourteen silicon atoms). With the theoretical calculation of the structural and optical properties of silicon clusters, it is possible to evaluate the contribution of silicon agglomerates in the luminescent emission mechanism experimentally found in thin SRO films.
\end{abstract}

Keywords: Nano-Crystals; Silicon Clusters; Silicon-Rich Oxide; Luminescence; Magic-Number

\section{Introduction}

Canham [1] reported visible light emission from porous silicon at room temperature in 1990 and since then, silicon associated materials have received a huge interest and have been studied intensively for their relevance to the development of nano-electronics. In that sense, a material which has generated great interest is SRO thin film (Silicon Rich Oxide); this material exhibits optical properties in the same manner to porous silicon but is significantly less assailable.

$\mathrm{Si}$ nanocrystals (Si-nCs) embedded in dielectric matrices such as silicon dioxide exhibit unique optical and

"Corresponding author. electrical properties which are determined by quantum size and Coulomb blockade effects [2]. Si-nCs can emit and absorb light at energies which can be controlled by their sizes. This fundamental property of Si-nCs is very useful in 3rd generation solar cells [3].

Commonly, SRO is considered as a multi-phase material constituted of a mixture of silica $\left(\mathrm{SiO}_{2}\right)$, offstoichiometric oxides $\left(\mathrm{SiO}_{\mathrm{x}}, \mathrm{x}<2\right)$ and elemental silicon. After thermal treatment at temperatures above $1000^{\circ} \mathrm{C}$, the off-stoichiometric oxides, $\mathrm{SiO}_{\mathrm{x}}(\mathrm{x}<2)$, react to produce silicon nano-clusters, structures with different oxidation states with or without defects and silica [4]. Silicon nano-crystals (Si-nCs) and silicon agglomerates have been characterized in SRO films employing Transmis- 
sion Electron Microscopy (TEM) and Atomic Force Microscopy (AFM). The formation and the size of Si-nCs depend on the excess silicon and annealing parameters (time and temperature) and surely of type of carried gas used. When the number of valence electrons in the clusters is $8,20,40$, or 58 etc., it is well known that silicon clusters are "magic-number" [5]. The "magic-number" behavior of small size silicon clusters is frequently correlated with the trend of binding energy per atom as a function of cluster size [6].

The electronic configuration of an atom and the number of atoms in the cluster are two factors that play the major role in the cluster stability [7].

Over the past twenty years, medium-sized silicon clusters $\mathrm{Si}_{\mathrm{n}}(\mathrm{n}>10)$ have attracted much attention both experimentally [8] and theoretically [9]. Considerable effort has been devoted to determine the ground-state geometric structures, namely, the global minima as a function of the cluster size $\mathrm{n}$. For $\mathrm{n} \leq 7$, the global minima are firmly established by both ab initio calculations and Raman/infrared spectroscopy measurements; whereas for $\mathrm{n} \leq 12$ the global minima based on ab initio calculations [10-15] are well accepted.

For $13 \leq \mathrm{n} \leq 20$, unbiased search for the global minima has been undertaken based on either the genetic algorithm coupled with semi-empirical tight-binding (TB) technique $[16,17]$, or the single-parent evolution algorithm coupled with density-functional (DF) TB and density-functional theory (DFT) methods $[18,19]$. Set correctly the geometry corresponding to the global minimum energy is critical for a further evaluation, so reliable, of optical and structural properties, and thereby contribute properly to the understanding of the underlying mechanisms of luminescence.

Crystalline silicon has an indirect band gap, which means, every optical transition must be accompanied by the creation or annihilation of a phonon. Another disadvantage is due to the low band gap value $E_{\mathrm{g}, \mathrm{c}-\mathrm{Si}}=1.12 \mathrm{eV}$ (at Room Temperature) corresponding to a wavelength $\lambda_{\mathrm{g}, \mathrm{c}-\mathrm{Si}}=1107 \mathrm{~nm}$ : the radiation emitted by a light emitting diode (LED) built of c-Si corresponds with infrared and then is non-visible by the human eye.

By usage of nano-scaled silicon structures the last mentioned disadvantage can be overcome. There are optical transitions in quantum confined states of Si nanostructures, which generate visible radiation. But the disadvantage of the indirect band gap still remains. Average PL decay times for Si-nCs with diameters $\mathrm{d} \sim 3.4 \mathrm{~nm}$ are reported to be $\tau_{\mathrm{PL}} \sim(100-500) \mu$ s at RT [20]

The most intense light emission observed in SRO films obtained by LPCVD technique has been reported in films with approximately 5\% excess silicon, but silicon nanocrystals were not observed in those films [21]. It is possible that silicon small size agglomerates $\left(\mathrm{Si}_{\mathrm{n}}, \mathrm{n}<20\right)$ were presented in these particular films $\left(\mathrm{R}_{0}=30\right)$ which would hardly be detected due to atomic instead nano scale. Size regimes in the evolution of semiconductor spectroscopic properties were introduced by Efros [22]. Semiconductors sizes can be labeled with increasing size as molecular ( $\mathrm{n}<50$ atoms), quantum $\operatorname{dot}\left(50 \leq \mathrm{n} \leq 10^{5}\right.$ atoms), polariton $\left(10^{5} \leq \mathrm{n} \leq 10^{9}\right.$ atoms), and finally ( $\mathrm{n}>$ $10^{9}$ atoms) for bulk semiconductor species.

In this work, we calculated theoretically the IR, UVVis and Raman spectra and a selected set of properties of small and medium size silicon agglomerates (agglomerates size less than $1.5 \mathrm{~nm}$ ). The equilibrium energy calculated of several propose $\mathrm{d} \mathrm{Si}$ clusters at ground state and the six first excitation states calculated result very useful to evaluate the possible contribution to the PL from different silicon structures present in SRO films.

\section{Theory of Electronic States in Nanocrystals}

The excitation of nanocrystals with photons can only happen from electronic states in the valence band to electronic states in the conduction band. To obtain the electronic states in a nano-crystal the assumption that nanocrystals have a spherical shape is used. S. V. Gaponenko [23] used spherical coordinates $r, \theta$ and $\phi$ and the Hamiltonian:

$$
H=-\frac{\hbar^{2}}{2 m} \nabla^{2}+U(r)
$$

where $U(r)$ is the total potential energy of the electron inside the quantum dot. In this Hamiltonian the Laplace operator in spherical coordinates must be used:

$$
\begin{aligned}
& H=-\frac{\hbar^{2}}{2 m r^{2}} \frac{\partial}{\partial r}\left(r^{2} \frac{\partial}{\partial r}\right) \\
& -\frac{\hbar^{2}}{2 m r^{2}} \frac{1}{\sin \theta}\left[\frac{\partial}{\partial \theta}\left(\sin \theta \frac{\partial}{\partial \theta}\right)+\frac{1}{\sin \theta} \frac{\partial^{2}}{\partial \phi^{2}}\right]+U(r)
\end{aligned}
$$

Due to the spherical symmetry of the potential a separation of the wave function leads to the following wave function:

$$
\psi_{n, l, m}(r, \theta, \phi)=\frac{u_{n, l}(r)}{r} Y_{l m}(\theta, \phi)
$$

where $Y_{l m}(\theta, \phi)$ is the spherical functions, $n$ is the principal quantum numbers, $l$ is the orbital number and $m$ the magnetic number. The angular momentum $L$ is determined by the orbital number $l$ :

$$
L=\hbar^{2} l(l-1) \quad l=0,1,2, \cdots, n-1
$$

The component parallel to the $z$ axis is determined by the magnetic quantum number $m:^{1}$

$$
{ }^{1} \dagger \text { Bessel function : } j l(\xi)=(-\xi)^{\prime}\left(\frac{1}{\xi} \frac{\partial}{\partial \xi}\right) l \frac{\sin (\xi)}{\xi}
$$




$$
L_{z}=\hbar m \quad m=-l,-l+1,-l+2, \cdots, l-1, l
$$

Inserting into the Schrödinger equation $u_{n, l}(r)$ must satisfy the equation:

$$
-\frac{\hbar^{2}}{2 m} \frac{\mathrm{d}^{2} u}{\mathrm{~d} r^{2}}+\left[U(r)+\frac{\hbar^{2}}{2 m r^{2}} l(l+1)\right] u=E u
$$

In order to obtain a solution to this equation the potential is approximated as infinitely high which leads to the following expression for the energy values of the electronic states in a spherical nano-crystal:

$$
E_{n l}=\frac{\hbar^{2} \chi_{n l}^{2}}{2 m a^{2}}
$$

where $\chi_{n l}$ are the roots of the spherical Bessel functions ${ }^{\dagger}$.

In the real space the electron and the hole are interacting via coulomb attraction. This bound pair of electron and hole is known as excitons. Quantum confinement occurs if the Bohr radius, of the excitons is larger than the size of the nano-crystal. Due to the high potential of the silicon dioxide (approximately $9 \mathrm{eV}$ ) which surrounds the silicon nanocrystals the excitons are confined within the volume of the nano-crystal. This leads to further changes of the band structure and the emissions spectrum.

Starting from the energy value already calculated $\left(E_{n l}\right)$ and applying perturbation theory it is possible to obtain a correction factor due to the effective mass of the electron and hole respectively.

Additionally, the Coulomb interaction between the electron and the hole has to be considered. A combination of both approaches leads to the Hamiltonian in the lowest excited state:

$$
H=-\frac{e^{2}}{\epsilon\left|r_{e}-r_{h}\right|}-\frac{\hbar^{2}}{2}\left[\frac{\nabla_{e}^{2}}{m_{e}}+\frac{\nabla_{h}^{2}}{m_{h}}\right]+\text { polarization terms }
$$

With the distance of electron and hole $r_{e}-r_{h}$, their effective masses $m_{e}$ and $m_{h}$ respectively and the dielectrical constant $\epsilon$.

We assume in Equation (1) that the total potential energy $U(r)$ to be of the following form:

$$
U(r)=U_{o}(r)+V_{s p}(r)
$$

The second part $V_{s p}(r)$ describes an interaction between the electron and its image, arising due to the charge polarization on the boundary between the silicon nanocrystal and its dielectric surrounding. $V_{s p}(r)$ is often referred to as a self-polarization term. It can be represented as:

$$
V_{s p}(r)=\frac{e^{2}\left(\varepsilon_{s}-\varepsilon_{d}\right)}{2 \varepsilon_{s} R} \sum_{l=0}^{\infty} \frac{l+1}{l \varepsilon_{s}+(l+1) \varepsilon_{d}} \frac{r^{2 l}}{R^{2 l}}
$$

where $\varepsilon_{s}$ and $\varepsilon_{d}$ are the static dielectric constants of silicon and the dielectric matrix, respectively. The polarization terms enter because we must consider the cor- rect form of the Coulomb interaction in the presence of the crystallite surface. An analytical approximation for the lowest eigenvalue (i.e., the first excited electronic state) is:

$$
E \cong E_{G}-\frac{1.8 e^{2}}{\epsilon R}+\frac{\hbar^{2} \pi^{2}}{2 R^{2}}\left[\frac{m_{e}+m_{h}}{m_{e} m_{h}}\right]+\text { smaller terms }
$$

where $E_{G}$ is the bulk band gap, $R$ is the size of the nanocrystal, the term $\propto$ to $R^{-1}$ is the coulomb term and the term $\propto$ to $R^{-2}$ is the shift as a result of quantum localization of electrons and holes (quantum confinement). This simple formula is possible because the correlation between electron and hole positions, induced by the Coulomb interacttion, is not strong. The major effect is additive, independent confinement energies for electron and hole.

Latest energy equation connects in a very simple way the emitted wavelength of a nano-crystal to its size, by means of:

$$
E_{G}=h v \approx \frac{1239.7}{\lambda[\mathrm{nm}]}
$$

In 1984 Brus [24] suggested the first theoretical calculation for semiconductor nanoparticles based on "effective mass approximation" (EMA). This approximation assumed that an exciton is confined to a spherical volume of the crystallite and the mass of electron and hole is supplanted with effective masses $\left(m_{e}^{*}\right.$ and $\left.m_{h}^{*}\right)$ to define the wave function.

$$
E_{g}=E_{\text {bulk }}+\frac{h^{2}}{8 R^{2}}\left[\frac{m_{e}^{*}+m_{h}^{*}}{m_{e}^{*} m_{h}^{*}}\right]-\frac{1.786 e^{2}}{4 \pi \varepsilon_{0} \varepsilon_{r} R^{2}}
$$

$\varepsilon_{0}$ is the permittivity of vacuum and $\varepsilon_{r}$ is the relative permittivity. Four year later, in 1988 Kayanuma [25] accounted for the electron-hole spatial correlation effect and modified the Brus Equation, including a taking away term proportional to Rydberg energy.

\section{Analysis and Discussion of the Results Obtained}

For many years, different methods have been used for preparation of silicon nano-crystals, for instance, chemical vapor deposition [26], Si ion implantation [27], colloidal synthesis [28], magnetron sputtering [26], and electron beam evaporation [29]. A high-temperature thermal treatment at temperatures above $1000^{\circ} \mathrm{C}$ is generally required in order to produce the crystallites. All these techniques allow one to form silicon nCs with sizes mainly ranging from $2-6 \mathrm{~nm}$, and it is possible obtain silicon nCs with sizes less than $2 \mathrm{~nm}$ in SRO films as deposited with Ro $=30$ prepared using LPCVD technique. Their electronic and optical properties depend on the preparation conditions and method of fabrication. However, there are some common properties typical for silicon 
$\mathrm{nCs}$, independent of the fabrication technique employed. In particular, the nanocrystals' surroundings, either vacuum or some host material like SRO, represent a high potential barrier for carriers of both kinds. Such a barrier is often referred to as a confining potential that mainly defines the energy spectrum of the nano-crystal.

Figure 1 displays the optical band gap of silicon nanocrystals obtained from optical absorption (unfilled symbols) and PL data (filled symbols). Dashed and continuous lines are calculated values with and without excitonic correction, respectively.

Silicon nCs are capable of emitting electromagnetic energy in the visible spectrum. This is in contrast with bulk silicon, in which energy of the interband transition corresponds to the silicon band gap energy of $1.12 \mathrm{eV}$.

The variation of the photon frequency in nanocrystals compared to the bulk material is a universal phenomenon taking place in huge of semiconductor materials. The energy of the emitted photon increases as the nano-crystal size decreases. Such an increase is usually called a "blueshift" because the photon energy shifts toward the shorterwavelength side of the visible spectrum.

This blue-shift is illustrated for $\mathrm{Si} \mathrm{nCs}$ in Figure 2. Here, the mean $\mathrm{nC}$ size is controlled via the silicon excess concentration, with the smallest nCs occurring in the most silicon deficient samples. Reduction in intensity on the silicon-poor side of the compositional map is due to the lower number density of nCs, and on the silicon-rich side it is due to the opening of non-radiative pathways in large and highly interconnected nano-clusters.

There is a legitimately large uncertainly in the calculated values of the optical gaps as a function of $\mathrm{nCs}$ diameter. Doubtless, several factors influencing the accuracy of the optical-gap measurements are as follows. First, the nanocrystals studied by different research groups have been prepared using different techniques. As a result, the

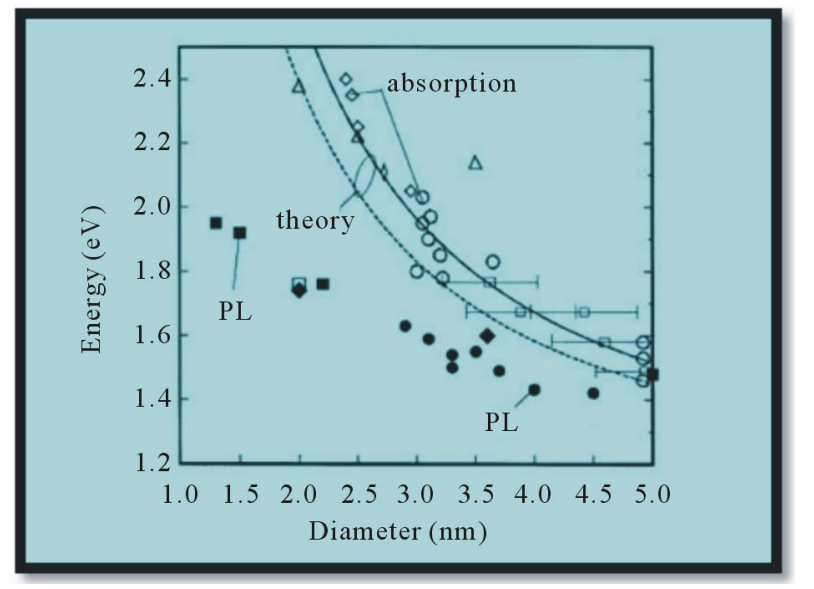

Figure 1. Optical band gap of silicon nano clusters. Theoretical calculus vs experimental data compilated by Delerue [31].

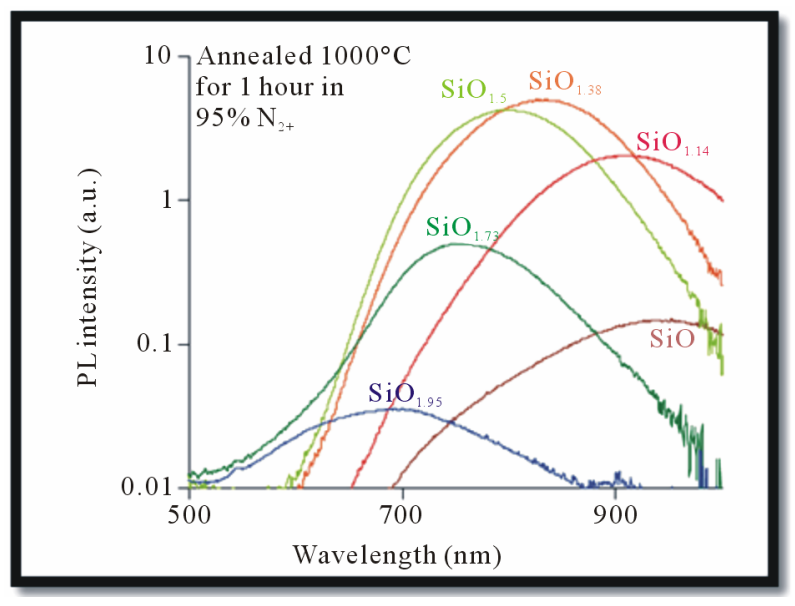

Figure 2. PL spectra of silicon $\mathrm{nCs}$ in $\mathrm{SiO}_{2}$. The 200-nmthick samples were approximately identical except for the amount of excess silicon [32].

nCs have different surroundings, surface bonds, and shapes, all of which could lead to scatter in the experimental data. Second, it is difficult to determine exactly the dot sizes and the size distribution in luminescent agglomerate of nCs. Finally, using the mean size in a cluster of nCs in a plot like Figure 1 can be confusing, since it is possible that the observed PL peak does not correspond exactly to the mean size but instead to the largest PL rate.

Theoretically, the problem persists mainly due to the difficulty to define an appropriate parameter for determining the diameter (equivalent). By simplicity a sphere is used in most of the models suggested, since the actual shape of the agglomerates formed is totally irregular. Figure 3 shows the calculated Van Der Waal surfaces for isomers $\mathrm{Si}_{7}$. In this case, only the isomer with lowest energy is acceptably symmetric. And even then it is difficult to choose the appropriate size.

Thus, for example the greatest distance found in isomer $7 \mathrm{~A}$ is which can be measured from either silicon atoms placed in the vertex of a pentagon to its second nearest neighbor obtaining values in range of 4.050 to $4.053 \AA$ for $\mathrm{Si}-\mathrm{Si}$ not bonded in ten possible measures; of 2.506 to $2.508 \AA$ in five measures corresponding to silicon atoms contiguous around the pentagon (bond distance), the distance between silicon atoms in two pyramid corners or vertex is $2.568 \AA$ and the distance between a silicon atom in pentagon to the silicon atom in pyramid corner is 2.486 to $2.488 \AA$ (ten bond distance values).

Assuming for silicon a Van der Waals radii of $2.1 \AA$, then the diameter for $\mathrm{Si}_{7}$ isomer $7 \mathrm{~A}$ could be in range 0.4586 to $0.6153 \mathrm{~nm}$. So, how can we set the most appropriate diameter or crystallite size?

For solve this, we employ a space-filling model, also known as a calotte model or CPK models, is a type of three-dimensional molecular model where the atoms are represented by spheres whose radii are proportional to the 
radii of the atoms and whose center-to-center distances are proportional to the distances between the atomic nuclei, all in the same scale. CPK models are distinguished from other 3D representations, such as the ball-and-stick and skeletal models, by the use of "full size" balls for the atoms. They are useful for visualizing the effective shape and relative dimensions of the molecule, in particular the region of space occupied by it. Table 1 displays values for CPK volume and CPK area for isomers $\mathrm{Si}_{7}$. For isomer $7 \mathrm{~A}$, using CPK volume we obtain $d_{1}=6.987 \AA(\approx 0.7 \mathrm{~nm})$ and $d_{2}=7.400 \AA(\approx 0.74 \mathrm{~nm})$ when we use CPK area. Finally, we can co-relate CPK area and CPK volume, obtaining the diameter $[\AA]$ with equation:

$$
\frac{6 \times \mathrm{CPK}_{\text {volume }}}{\mathrm{CPK}_{\text {AREA }}}=\frac{6 \times \frac{4}{3} \pi\left(\frac{D}{2}\right)^{3}}{4 \pi\left(\frac{D}{2}\right)^{2}}=D
$$

Substitution of values gives $D=6.2295 \AA$, for isomer 7 A.

Figure 4(a) corresponds with AFM image 3D. Adjunct to coordinates $(0,3.5)$ it is possible to find thickness less than $5 \mathrm{~nm}$ [33]. Whereas in Figure 4(b) adjacent to coordinates $(0,2.8)$ it is possible to find thickness less than 1 nm.

In Figure 5(a) we can appreciate roughness less than 1 $\mathrm{nm}$ for SRO films as deposited with a Ro $=20$ and less than $5 \mathrm{~nm}$ for films deposited with Ro $=10$ and Ro $=30$. Whereas Figure 5(b) is a 2D AFM image for SRO film deposited by LPCVD, in blue line $(\mathrm{Ro}=30)$ we are able to find height less than $1 \mathrm{~nm}$. For Ro $=20$ (red line) is possible observe height less than $1 \mathrm{~nm}$ around $\chi \approx 1.2 \mu \mathrm{m}$. Finally, for $\mathrm{Ro}=10$ (black line) there is a small region with altitudes less than $1 \mathrm{~nm}$ everywhere $\chi \approx 1.95 \mu \mathrm{m}$. The highest agglomerates found correspond to Ro $=10$ and it is approximately $25 \mathrm{~nm}$.

\subsection{Structural and Optical Properties for $\mathbf{N}=7$}

For $\mathrm{Si}_{7}$ we have evaluated four geometric isomers of low- energy reported by Raghavachari and Rohlfing [6] No qualitative change in the geometry of these isomers was found except the capped trigonal prism. The lowest-energy isomer of $\mathrm{Si}_{7}$ corresponds with structure 7A, a pentagonal bipyrimid with $\mathrm{D}_{5 \mathrm{~h}}$ symmetry, in accordance with the experiment [34] and previous theoretical studies [6]. Note that the structures of small silicon clusters are different from the tetrahedral coordination characteristic of bulk silicon. Table 2 contains specific bonds calculated information for $\mathrm{Si}_{7}$ structures. Table 1 displays calculated structural and geometric properties for $\mathrm{Si}_{7}$ nano-cluster. The most stable structure (7A) presents the lowest Dipole, CPK Area $\left(\AA^{2}\right)$ CPK volume $\left(\AA^{3}\right)$, ovality and polarizability parameters and the highest symmetry and band gap. Figure 6 shows ovality and polarizability calculated parameter for $\mathrm{Si}_{7}$ isomers. Ovality is a measure of how the shape of the molecule approaches a sphere or cigar. Ovality is described by the ratio of volume and area.

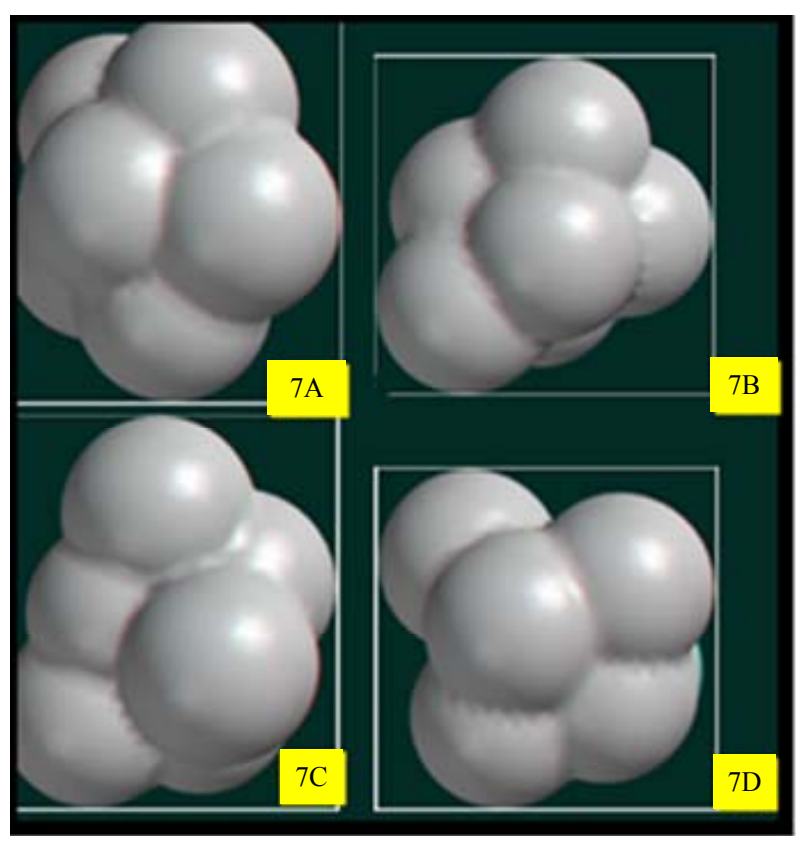

Figure 3. Calculated Van Der Waal surfaces for isomers $\mathrm{Si}_{7}$.

Table 1. Calculated Properties for $\mathrm{Si}_{7}$ nano-cluster.

\begin{tabular}{|c|c|c|c|c|c|c|c|c|c|c|}
\hline Isomer & E (au) & $\begin{array}{c}\text { E LUMO } \\
(\mathrm{eV})\end{array}$ & $\begin{array}{c}\text { E HOMO } \\
(\mathrm{eV})\end{array}$ & $\begin{array}{c}\text { band gap } \\
\mathrm{eV}\end{array}$ & $\begin{array}{l}\text { Dipole } \\
\text { (debye) }\end{array}$ & $\begin{array}{c}\text { CPK } \\
\text { Area }\left(\AA^{2}\right) \\
\end{array}$ & \begin{tabular}{|c|c} 
CPK \\
Volume $\left(\AA^{3}\right)$
\end{tabular} & Ovality $^{* *}$ & Nsymop & polarizability \\
\hline $7 \mathrm{~A}$ & -2026.40489 & -3.17 & -6.35 & 3.17711489 & 0.01 & 172.06 & 178.60 & 1.12184512 & 4 & 55.1102671 \\
\hline $7 \mathrm{~B}$ & -2026.34772 & -3.70 & -5.60 & 1.89752335 & 1.12 & 174.00 & 180.46 & 1.12674305 & 1 & 55.5653083 \\
\hline $7 \mathrm{C}$ & -2026.34325 & -3.25 & -5.61 & 2.36333424 & 0.25 & 183.44 & 185.93 & 1.16445201 & 1 & 55.8984076 \\
\hline $7 \mathrm{D}$ & -2026.34330 & -3.26 & -5.62 & 2.36498471 & 0.26 & 183.56 & 185.96 & 1.16504567 & 2 & 55.9003733 \\
\hline
\end{tabular}

${ }^{*}$ Polarizability $=0.08 \times$ VDW_Volume $-13.0352 \times$ hardness $+0.979920 \times$ hardness $^{2}+41.3791 ;{ }^{* *}$ Ovality $=A /\left(4 \times \pi \times((3 \times V) / 4 \times \pi)^{(2 / 3)}\right)$;

hardness $=-\left(E_{\text {номо }}-E_{\text {Luмо }}\right) / 2$. 


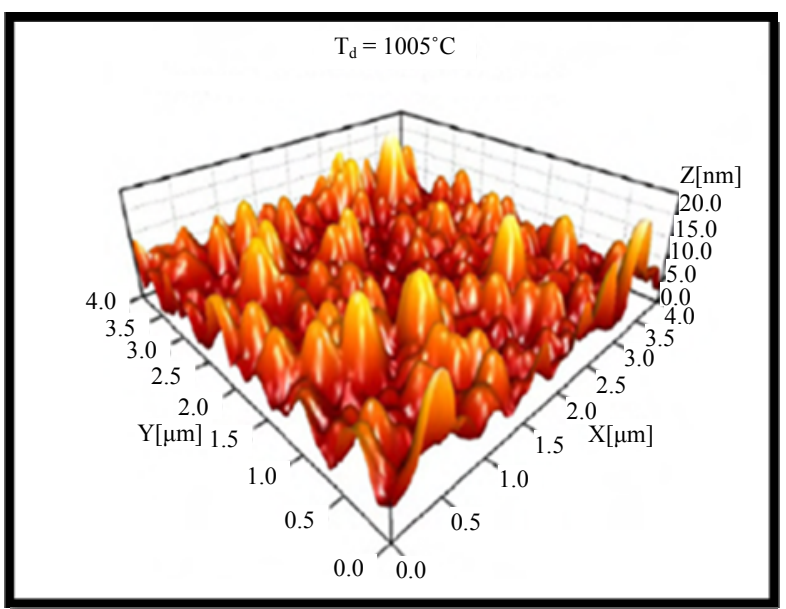

(a)

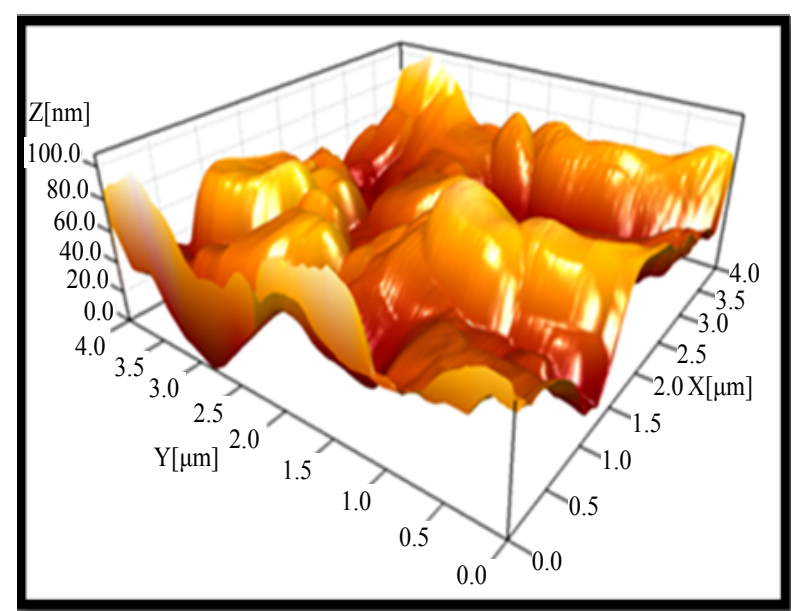

(b)

Figure 4. (a) AFM image 3D obtained of a SRO film deposited by HFCVD at $1005^{\circ} \mathrm{C}$; (b) AFM image 3D obtained of a SRO film deposited by HFCVD on silicon substrate.

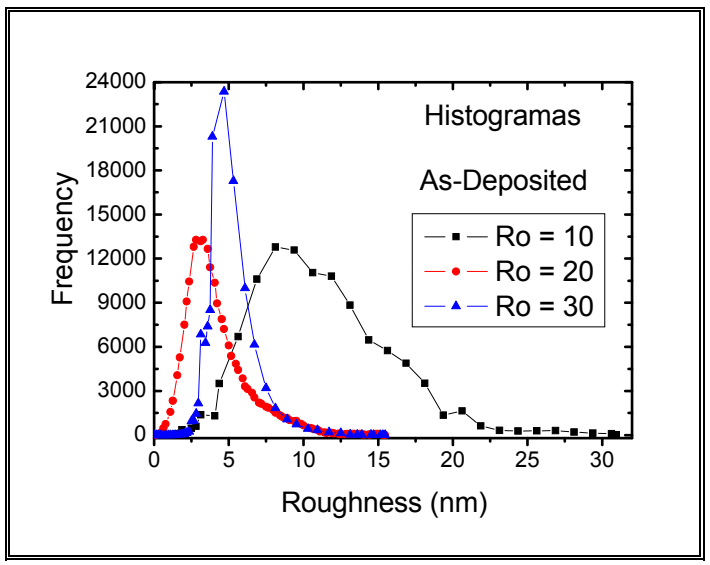

(a)

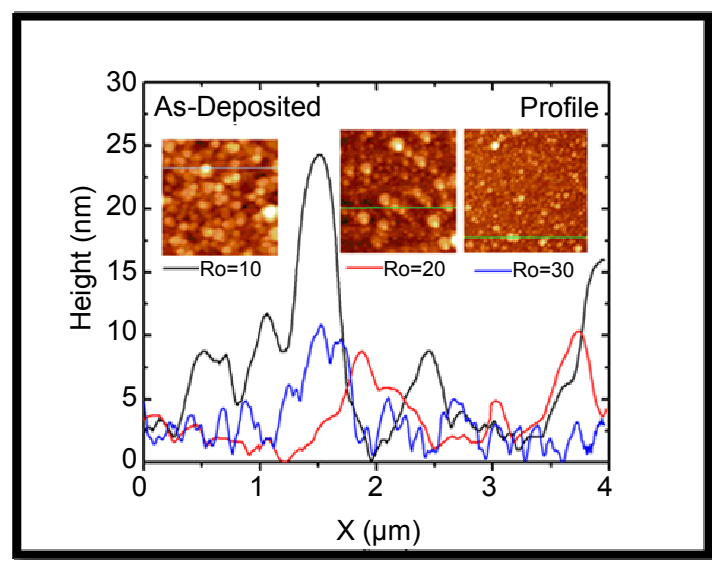

(b)

Figure 5. (a) Histogram of roughness [nm] for SRO films as deposited; (b) 2D Image that shows the selection of the Roughness and profile characteristics for statistical analysis of SRO10, 20 and 30 As-deposited films on Silicon for a scan size of $4 \times$ $4 \mathrm{\mu m}^{2}$.

Table 2. Small nanoclusters $\mathrm{Si}_{7}$ exhibit a coordination different that found in bulk silicon (tetra coordinated).

\begin{tabular}{c|c|c|ccc|c}
\hline Isomer & $\begin{array}{c}\text { Number of Silicon } \\
\text { atoms with 2 bonds }\end{array}$ & $\begin{array}{c}\text { Number of Silicon } \\
\text { atoms with 3 bonds }\end{array}$ & $\begin{array}{c}\text { Number of Silicon } \\
\text { atoms with 4 bonds }\end{array}$ & $\begin{array}{c}\text { Number of Silicon } \\
\text { atoms with 5 bonds }\end{array}$ & $\begin{array}{c}\text { Number of Silicon } \\
\text { atoms with six bonds }\end{array}$ & $\begin{array}{c}\text { Total Number } \\
\text { of Si-Si bonds }\end{array}$ \\
\hline 7A & & 5 & 1 & 2 & 2 & 15 \\
7B & 1 & 1 & 3 & 3 & 2 & 15 \\
7C & & & 4 & 2 & 14 \\
7D & 1 & & & 3 & 15 \\
\hline
\end{tabular}

In Raman spectroscopy a vibrational mode is active due to a change in the polarizability during the vibration. On the other hand, a vibrational mode is active in FTIR as consequence of a change in the dipole moment during the vibration.

For isomer most stable (7A), FTIR spectra has a peak at $406 \mathrm{~cm}^{-1}$. Due to poor symmetry or anti-symmetry of isomers 7B, 7C and 7D there is a shift in frequency vibration values (until $529 \mathrm{~cm}^{-1}$ ) and appears additional small peaks, see Figure 7.

The second most intense peak in isomer $7 \mathrm{C}$ has a frequency of $436 \mathrm{~cm}^{-1}$ (indicated with a small red circle on Figure 7). Isomer 7D displays a similar peak in the frequency $439 \mathrm{~cm}^{-1}$. Luna et al. [33], have reported a peak at 


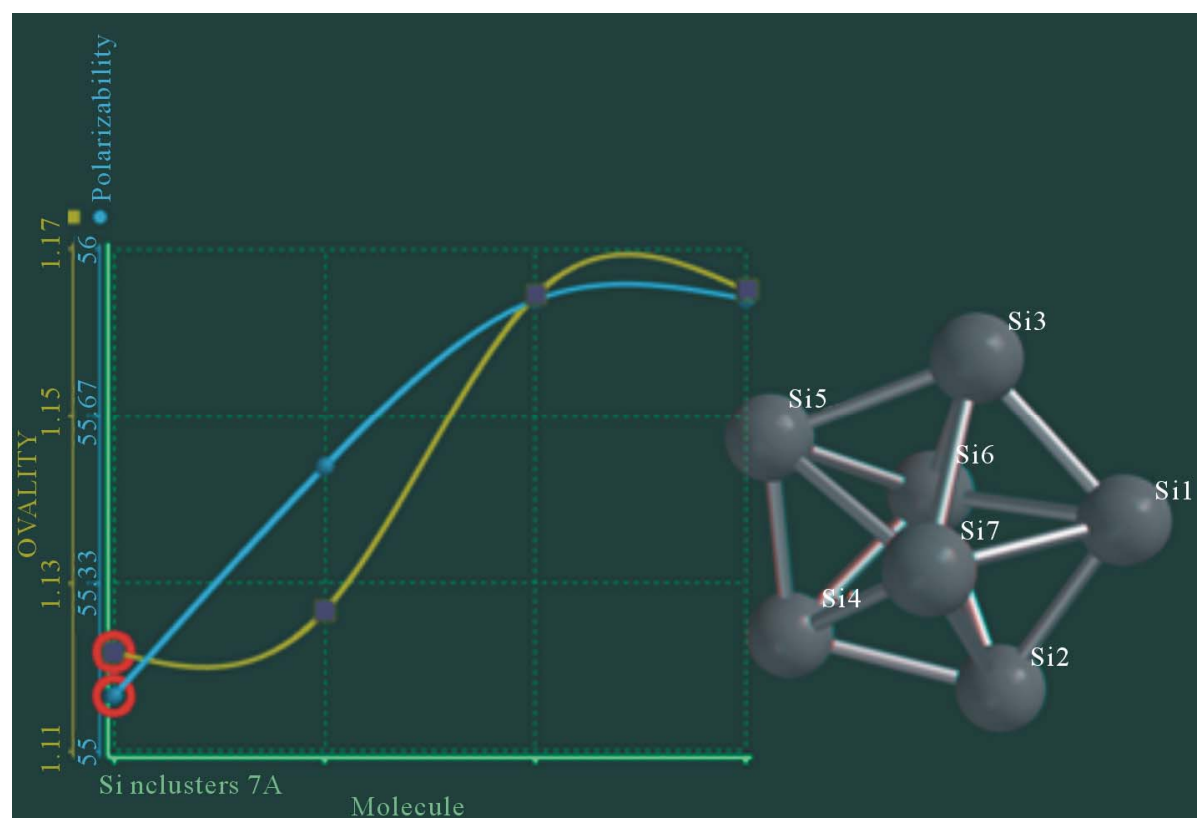

Figure 6. Ovality and polarizability plots for $\mathrm{Si} 7$ structures. Right side: Structure 7A (the lowest energy isomer).

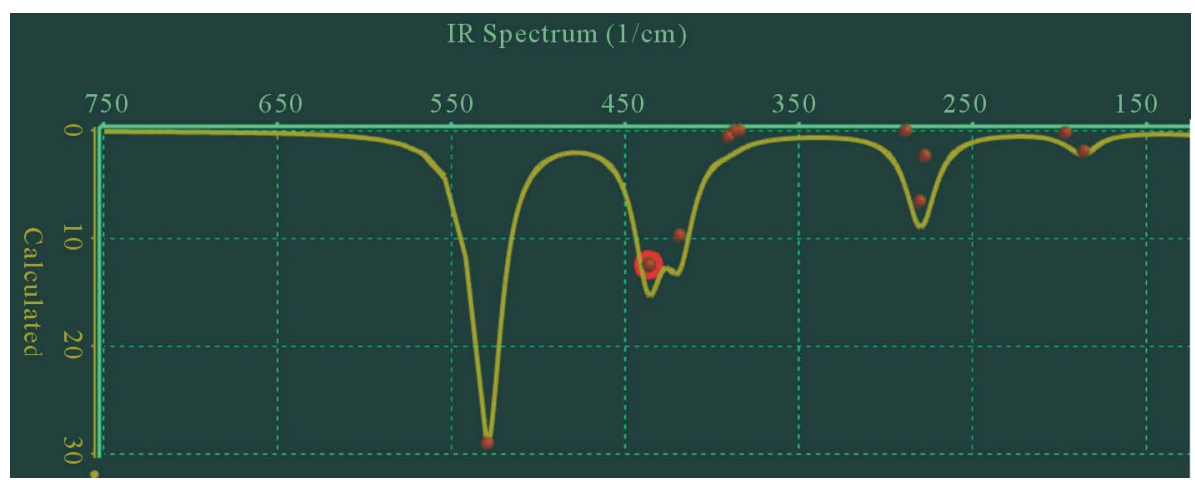

Figure 7. FTIR spectra for isomer 7C.

$440 \mathrm{~cm}^{-1}$, in SRO films deposited at $873^{\circ} \mathrm{C}$ by HFCVD, but they associated this vibration frequency with $\mathrm{Si}-\mathrm{O}$ rocking.

UV-Vis spectra calculated for isomers $\mathrm{Si}_{7}$ predict luminescence in visible region, except for most stable (isomer 7A) which results with emission in UV region. This fact could be associated with the similarity with tetrahedral coordination in bulk (there are five silicon atoms with four bonds each one and only two with five bonds). Figure 8 displays UV-Vis spectra for isomer 7D. In Table $\mathbf{3}$ we collect luminescence calculated data for isomers $\mathrm{Si}_{7}$.

The isomer $\mathrm{Si}_{7}$ with the highest stability (7A), results with violet emission expected and other isomers with less stability display a second expected peak in IR region.

\subsection{Structural and Optical Properties for $\mathrm{N}=12$}

Bahel and Ramakrishna [10,11] have examined 15 iso- mers of $\mathrm{Si}_{12}$ and shown that the pentagonal and tetragonal prismatic families are higher in energy than the trigonal prismatic family. Zhu et al. [35] obtain similar conclusion after examining several new low-energy isomers. For $\mathrm{Si}_{12}$ isomers found by Zhu [35], we have re-evaluated using $\mathrm{HF} / 6-31^{*}$, and we obtains some differences in results, see Table 4. Whereas Zhu et al. results indicate that isomer $12 \mathrm{~A}$ is the lowest-energy; our results give isomer $12 \mathrm{E}$ as the most stable structure.

Dipole moment calculated for isomers $\mathrm{Si}_{12}$ varies in range from 0.0 to 2.75 Debye's, and band gap fluctuates from 1.558 until $2.648 \mathrm{eV}$.

Table 5 contains the calculated properties for isomers $\mathrm{Si}_{12}$ organized from low to high energy. Sorted in this way, it is not possible correlate them with other parameter like dipole moment, band gap, polarizability, ovality or the size. The average size for isomers $\mathrm{Si}_{12}$, using CPK area and CPK volume models results $0.8595 \mathrm{~nm}$.Optical properties calculated for isomer $\mathrm{Si}_{12}$ are presented in right 


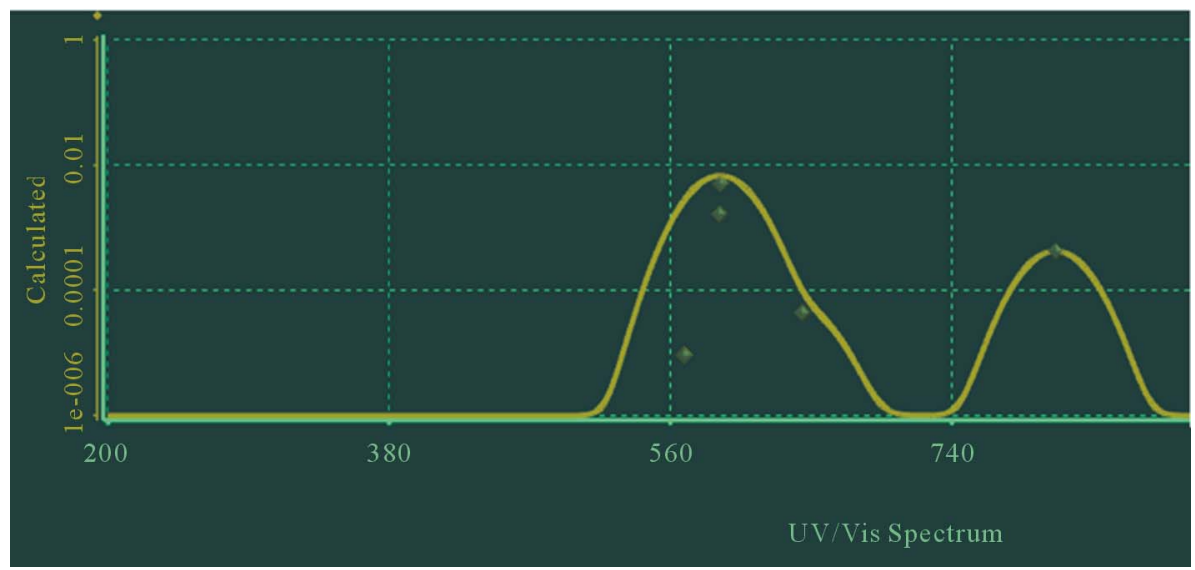

Figure 8. UV-Vis spectra for the isomer 7D.

Table 3. Calculated luminescence peaks for the isomers $\mathrm{Si}_{7}$.

\begin{tabular}{cccc|}
\hline Isomer & The Most intense peak emission [nm] & 2nd More intense peak emission [nm] & 3rd peak emission [nm] \\
\hline 7A & 382.41 (violet) & & \\
7B & 660.93 (red) & 930.99 (IR) & 777.58 (IR) \\
7C & 598.11 (orange) & 807.37 (IR) \\
7D & 591.98 (orange) & 806.26 (IR) \\
\hline
\end{tabular}

Table 4. Comparation of energies calculated of $\mathrm{Si}_{12}$ isomers.

\begin{tabular}{|c|c|c|c|c|}
\hline Isomer & $\mathrm{HF} / 6-31 \mathrm{G}^{*} \operatorname{ref}[\mathrm{ZZ}]$ & $\mathrm{MP} 2 / 6-31 \mathrm{G}^{*} \operatorname{ref}[\mathrm{ZZ}]$ & OUR RESULTS USING HF/6-31G* & Point Group \\
\hline $12 \mathrm{a}$ & -3466.75512 & -3467.97520 & -3473.81817 & $\left(\mathrm{C}_{2 \mathrm{v}}\right)$ \\
\hline $12 \mathrm{~b}$ & -3466.72241 & -3467.96359 & -3473.84833 & $(\mathrm{Cs})$ \\
\hline $12 \mathrm{c}$ & -3466.68583 & -3467.94708 & -3473.82730 & $(\mathrm{Cs})$ \\
\hline $12 d$ & -3466.72986 & -3467.94023 & -3473.829488 & $\left(\mathrm{C}_{2 \mathrm{v}}\right)$ \\
\hline $12 \mathrm{e}$ & -3466.74850 & -3467.93946 & -3473.85018 & (C1) \\
\hline $12 \mathrm{f}$ & -3466.68104 & -3467.92139 & -3473.83045 & (Cs) \\
\hline $12 \mathrm{~g}$ & -3466.71823 & -3467.91483 & -3473.82394 & $(C s)$ \\
\hline $12 \mathrm{~h}$ & -3466.67983 & -3467.91127 & -3473.82681 & $(C 3 v)$ \\
\hline $12 \mathrm{i}$ & -3466.56063 & -3467.90996 & -3473.80236 & $(D 4 h)$ \\
\hline $12 \mathrm{j}$ & -3466.69196 & -3467.90872 & -3473.82995 & $(C 2 v)$ \\
\hline $12 \mathrm{k}$ & -3466.63861 & -3467.90709 & -3473.81306 & $(C 5 v)$ \\
\hline 121 & -3466.68552 & -3467.89061 & -3473.84834 & $(C 2 v)$ \\
\hline ref [32] & MP3/6-31G* & MP4(SDQ)/6-316* & CCSD/6-31G* & $\operatorname{CCSD}(T) / 6-31 G^{*}$ \\
\hline $12 \mathrm{~A}$ & -3467.87303 & -3467.96718 & -3467.92573 & -3468.03985 \\
\hline $12 \mathrm{~B}$ & -3467.84017 & -3467.94730 & -3467.90060 & -3468.02069 \\
\hline
\end{tabular}


Table 5. Calculated properties for $\mathrm{Si}_{12}$ nano-clusters (sorted by energy value).

\begin{tabular}{|c|c|c|c|c|c|c|c|c|c|c|c|}
\hline Isomer & $\begin{array}{l}\text { Energy } \\
\text { homo } \\
\text { eV }\end{array}$ & $\begin{array}{c}\text { Energy } \\
\text { Lumo } \\
\mathrm{eV}\end{array}$ & $\begin{array}{l}\text { Dipole } \\
\text { Debye }\end{array}$ & $\begin{array}{l}\text { CPK } \\
\text { Area } \\
\left(\AA^{2}\right) \\
\end{array}$ & $\begin{array}{l}\text { CPK } \\
\text { Volume } \\
\left(\AA^{3}\right) \\
\end{array}$ & $\begin{array}{l}\text { band } \\
\text { gap } \\
\mathrm{eV}\end{array}$ & ovality & $\begin{array}{c}\mathrm{D}[\mathrm{nm}] \\
\text { (using } \\
\text { CPK Area } \\
\end{array}$ & $\begin{array}{c}\mathrm{D}[\mathrm{nm}] \\
\text { (using } \\
\text { CPK Volume }\end{array}$ & $\begin{array}{l}\text { FTIR frequency } \\
\text { of most } \\
\text { intense peak cm }{ }^{-1}\end{array}$ & $\begin{array}{l}\text { UV-Vis wavelength } \\
\text { of most intense } \\
\text { peak [nm] }\end{array}$ \\
\hline $12 \mathrm{E}$ & -5.77 & -3.60 & 0.46 & 247.51 & 288.66 & 2.17141970 & 1.17178681 & 0.8876 & 0.8200 & 485 & 826.45 (IR) \\
\hline $12 \mathrm{~L}$ & -5.80 & -3.88 & 0.70 & 249.32 & 290.45 & 1.92687531 & 1.17550443 & 0.8908 & 0.8217 & 415 & 720.43 (red) \\
\hline $12 \mathrm{~B}$ & -5.80 & -3.88 & 0.70 & 249.26 & 290.36 & 1.92499991 & 1.17546273 & 0.8907 & 0.8216 & 415 & 720.22 (red) \\
\hline $12 \mathrm{~F}$ & -5.82 & -3.17 & 2.75 & 245.18 & 288.52 & 2.64849119 & 1.16111964 & 0.8834 & 0.8198 & 435 & 562.76 (green) \\
\hline $12 \mathrm{~J}$ & -5.59 & -3.79 & 0.31 & 249.86 & 291.95 & 1.80151156 & 1.17402728 & 0.8918 & 0.8231 & 442 & 830.71 (IR) \\
\hline $12 \mathrm{C}$ & -5.69 & -3.77 & 1.19 & 250.22 & 291.07 & 1.91801037 & 1.17807238 & 0.8925 & 0.8222 & 408 & 635.2 (red) \\
\hline $12 \mathrm{H}$ & -5.78 & -4.07 & 0.00 & 254.22 & 296.04 & 1.70652814 & 1.18347241 & 0.8996 & 0.8269 & 354 & 733.33 (red) \\
\hline $12 \mathrm{G}$ & -5.43 & -3.37 & 0.98 & 251.45 & 292.34 & 2.06221174 & 1.18043949 & 0.8946 & 0.8234 & 427 & 576.75 (yellow) \\
\hline $12 \mathrm{~A}$ & -5.66 & -3.16 & 0.39 & 252.59 & 290.90 & 2.49877813 & 1.18970242 & 0.8967 & 0.8221 & 448 & 627.76 (red) \\
\hline $12 \mathrm{~K}$ & -5.54 & -3.99 & 0.44 & 259.84 & 294.83 & 1.55876248 & 1.21294270 & 0.9094 & 0.8258 & 492 & 772.49 (IR) \\
\hline $12 \mathrm{I}$ & -5.67 & -3.51 & 0.01 & 264.24 & 297.70 & 2.16061489 & 1.22555931 & 0.9171 & 0.8284 & 445 & 641.76 (red) \\
\hline
\end{tabular}

12D Fails

side of Table 5. FTIR calculated vibrations frequencies of 442,448 and $445 \mathrm{~cm}^{-1}$ (highlight in yellow) for isomers 12J, $12 \mathrm{~A}$ and $12 \mathrm{I}$ are in excellent agreement with experimental results and they were reported in SRO films deposited by HFCVD at temperatures in range of $750^{\circ} \mathrm{C}$ to $873^{\circ} \mathrm{C}$ ).

Also UV-Vis calculations are in Table 5. All $\mathrm{Si}_{12}$ isomers have an expected emission in visible range. We have selected the most intense peaks for each isomers and we plotted them in Figure 9. We can conclude that the likely most intense emission of isomers $\mathrm{Si}_{12}$ will be in color red.

Chemical Function Descriptors CFD's are descriptors given to a molecule in order to characterize or anticipate its chemical behavior or to identify commonality among molecules with different structures. They parallel terms in a chemist's vocabulary such as lone pair (to suggest the role of a hydrogen-bond acceptor) and sterically crowded (to suggest that getting close may be difficult). Figure 10 displays VDW surfaces for isomers $\mathrm{Si}_{12}(12 \mathrm{~A}, 12 \mathrm{~B}, 12 \mathrm{C}$ and $12 \mathrm{E}$ ) and includes sketchs $12 \mathrm{~F}$ to $12 \mathrm{~L}$ to represent CFD's for isomers $\mathrm{Si}_{12}(12 \mathrm{~F}$ to $12 \mathrm{~L})$. We can appreciate silicon atoms with coordination different respect to found in bulk. For instance, the isomer $12 \mathrm{H}$ has six silicon atoms with only three bonds, three silicon atoms with five bonds, two with six bond and one with seven bonds. That is, none of the twelve silicon atoms present in the isomer $12 \mathrm{H}$ is tetra coordinated.

Figure 11 includes FTIR spectra calculated for the most stable isomer $\mathrm{Si}_{12}$. The most intense peak with a frequency of $485 \mathrm{~cm}^{-1}$, corresponds to silicon atoms vibration that contains only three bonds. UV-Vis spectrum for isomer 12E is shown in Figure 12.

In this case, luminescence is observed in a wide interval of visible region and it extends to near IR, beginning in $574.67 \mathrm{~nm}$ and ending in $826.43 \mathrm{~nm}$ we can easily identify six emission states.

\subsection{Structural and Optical Properties for $\mathrm{Si}_{8}$ Isomers}

In 1988 Raghavachari and Rohlfing [6] reported seven low-energy isomers $\mathrm{Si}_{8}$ on the basis of the HF/6-31G(d) level of theory. Later, Xiaolei et al. [36] in 2003 reported eight isomers $\mathrm{Si}_{8}$, after optimizing the geometry at the MP2/6-31G(d) level followed by the total-energy calculation at the $\operatorname{CCSD}(\mathrm{T}) / 6-31 \mathrm{G}(\mathrm{d})$ level. Among the seven isomers originally cited, six geometric isomers, have the same structure as Xiaolei [36] suggested despite of some differences in energy ordering and geometric parameters due to different levels of theory employed. We evaluated full geometry optimizations followed by the total-energy calculation at the $\mathrm{HF} / 6-31 \mathrm{G}^{*}$ level, for eight structures suggested by Xiaolei [36], who reported isomer $8 \mathrm{~A}$ as the lowest energy $\mathrm{Si}_{8}$. Our results indicate that isomer $8 \mathrm{E}$ has the lowest energy. For isomers $\mathrm{Si}_{8}$, FTIR spectra are displayed in Figure 13.

In this case, there are 18 degree freedoms and most of them correspond with frequency vibrations of very low intensity. In Table 6 we collect numerical data. For isomers $8 \mathrm{C}, 8 \mathrm{G}$ and $8 \mathrm{~B}$, the highest vibration intensity corresponds with the maximum wavenumber.

In right column of Table 7 we include the wavelength of the energy level with the highest emission. All results obtained predict emission in visible region for isomers $\mathrm{Si}_{8}$. A selected set of $\mathrm{Si}_{8}$ isomers UV-Vis spectra are shown in Figure 14.

Figure 15 displays agglomerate's shape and coordination isomers's $\mathrm{Si}_{8}$. We can appreciate sub-coordinated (tri) and supra-coordinated (penta and hexa) silicon atoms, 


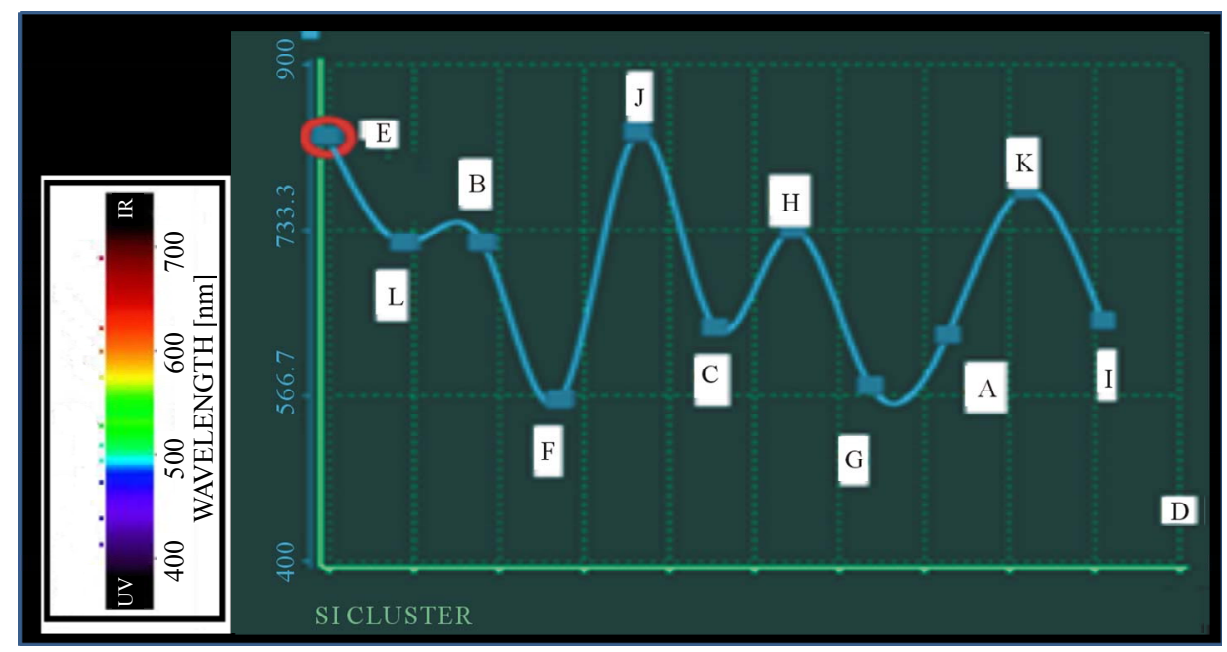

Figure 9. Wavelength ${ }_{\max }$ for isomers $\mathrm{Si}_{12}$.

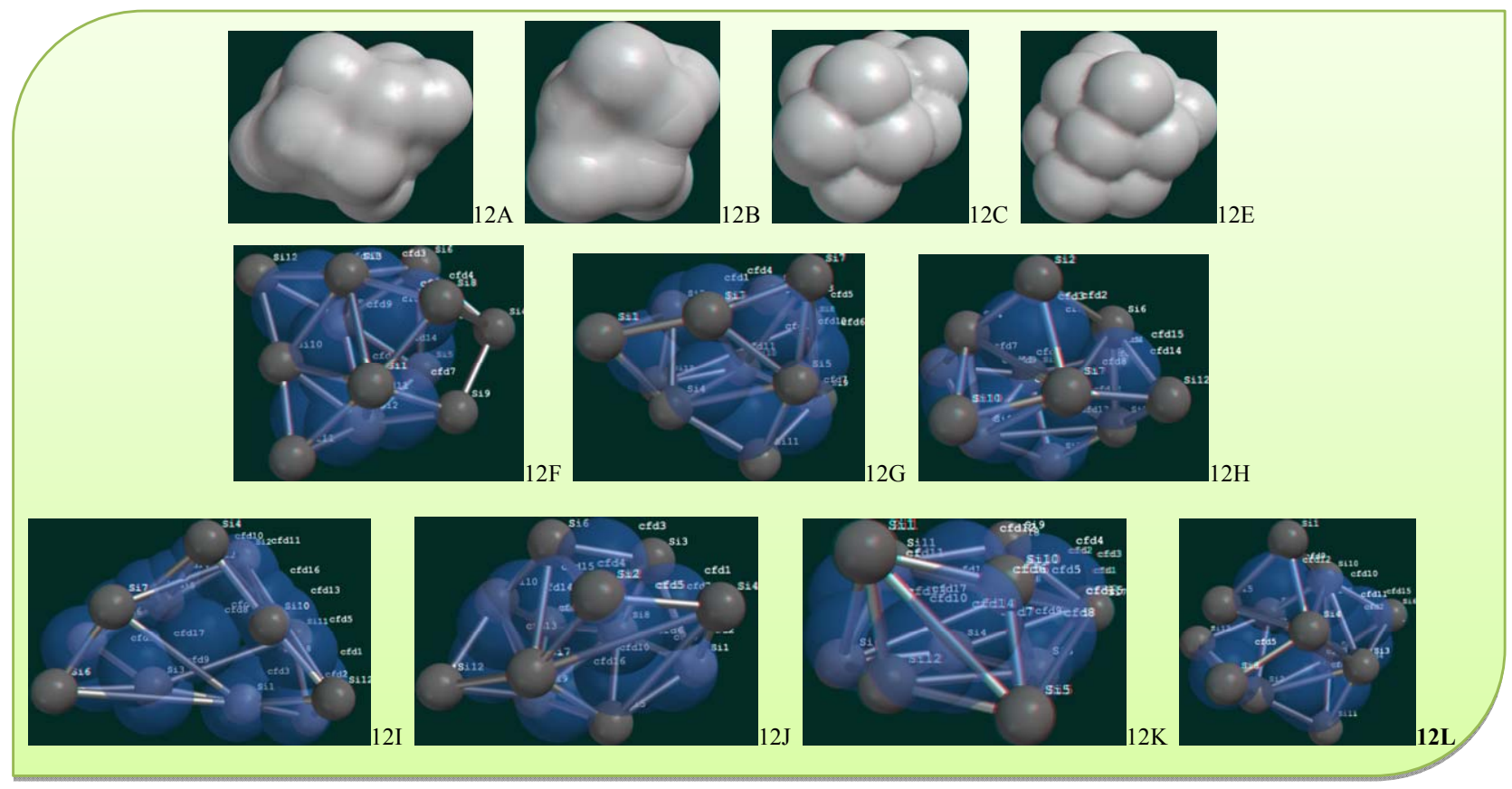

Figure 10. Sketch 12A to $12 \mathrm{E}$ display VDW surfaces for isomers $\mathrm{Si}_{12}(\mathrm{~A}, \mathrm{~B}, \mathrm{C}$ and $\mathrm{E})$. $12 \mathrm{~F}$ to12L represent $\mathrm{CFD}$ for isomers $\mathrm{Si}_{12}$ (F to L).

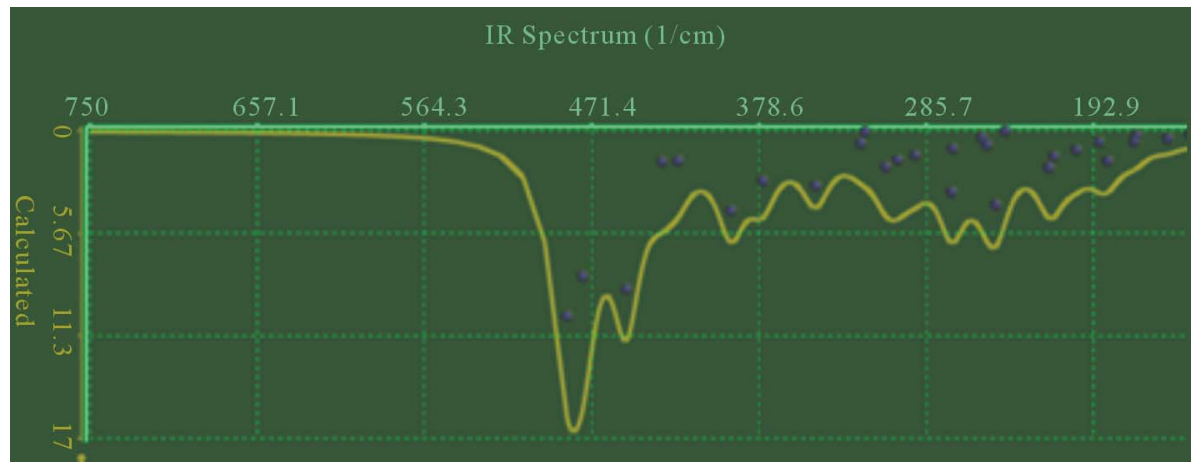

Figure 11. IR spectra calculated for silicon isomer with the lowest-energy $12 \mathrm{E}$. 


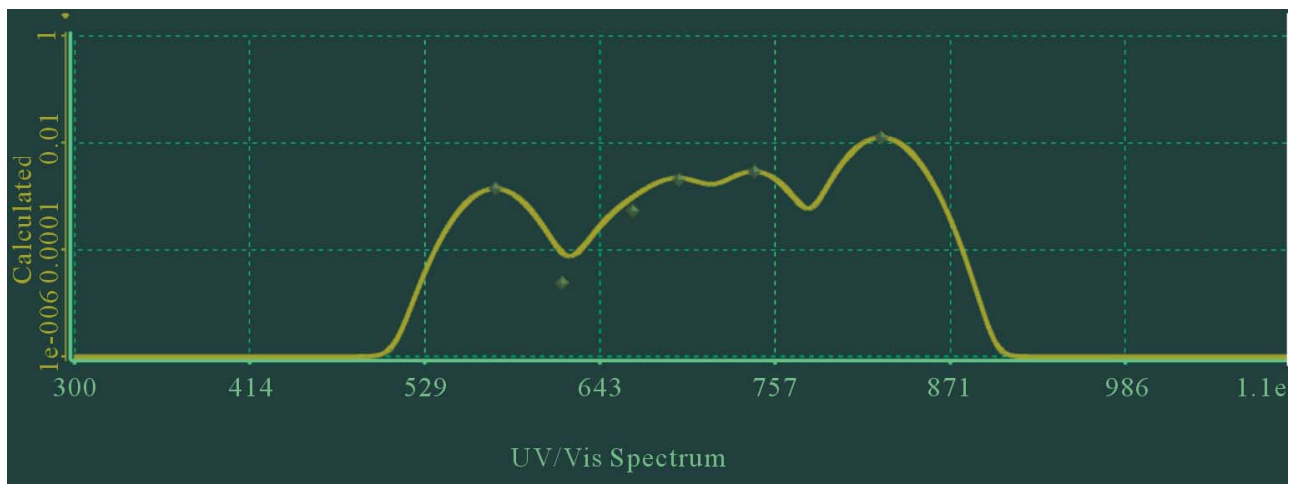

Figure 12. Luminescence spectra calculated for silicon isomer 12E.

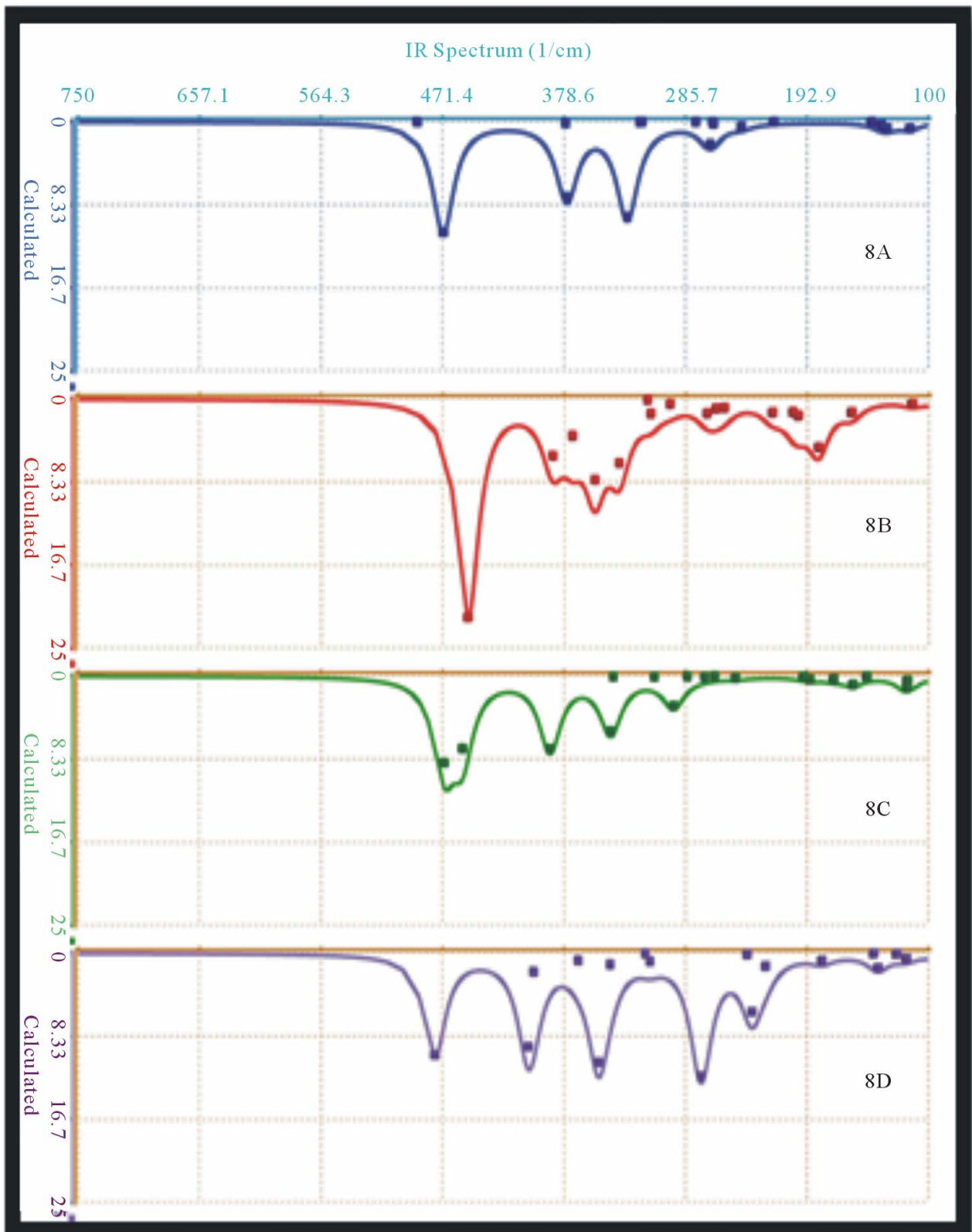

Figure 13. FTIR calculated spectra for isomers $\mathrm{Si}_{8}$ (A to D). 
Table 6. Calculated properties for isomers $\mathrm{Si}_{8}$.

\begin{tabular}{|c|c|c|c|c|c|c|c|c|c|c|}
\hline Isomer & $\begin{array}{c}\text { Energy } \\
\text { [hartree] }\end{array}$ & $\begin{array}{l}\text { E } \\
\text { HOM } \\
\mathrm{O}[\mathrm{eV}]\end{array}$ & $\begin{array}{c}\text { E } \\
\text { LUMO } \\
{[\mathrm{eV}]}\end{array}$ & $\begin{array}{l}\text { Band } \\
\text { gap } \\
{[\mathrm{eV}]}\end{array}$ & $\begin{array}{l}\text { Dipole } \\
\text { moment } \\
\text { [debye] }\end{array}$ & $\mid \begin{array}{c}\text { CPK } \\
\text { AREA } \\
\left(\AA^{2}\right)\end{array}$ & $\begin{array}{c}\text { CPK } \\
\text { VOLUME } \\
\left(\AA^{3}\right)\end{array}$ & $\begin{array}{c}\mathrm{D}=\text { NANO CRYSTAL } \\
\text { SIZE [nm], } \\
\text { using equation } 14\end{array}$ & $\begin{array}{l}\text { Number } \\
\text { of Si-Si } \\
\text { bonds }\end{array}$ & $\begin{array}{c}\text { CAN } \\
\text { (Equation (15)) }\end{array}$ \\
\hline $8 \mathrm{~A}$ & -2315.85400 & -5.48 & -3.81 & 1.66577122 & 0.00 & 190.10 & 202.88 & 0.640326546 & 19 & 4.75 \\
\hline $8 \mathrm{~B}$ & -2315.84487 & -5.40 & -3.90 & 1.49418089 & 0.94 & 189.68 & 203.19 & 0.642714381 & 17 & 4.25 \\
\hline $8 \mathrm{C}$ & -2315.84982 & -5.66 & -3.40 & 2.25498620 & 0.99 & 190.19 & 203.73 & 0.642716601 & 17 & 4.25 \\
\hline $8 \mathrm{D}$ & -2315.84767 & -5.10 & -3.33 & 1.76459166 & 0.80 & 193.41 & 203.76 & 0.632105836 & 16 & 4.00 \\
\hline $8 \mathrm{E}$ & -2315.86794 & -5.80 & -3.21 & 2.58956912 & 0.00 & 191.09 & 203.00 & 0.637395306 & 18 & 4.50 \\
\hline $8 \mathrm{~F}$ & -2315.86179 & -6.06 & -3.86 & 2.19571567 & 0.46 & 191.99 & 203.99 & 0.637486965 & 18 & 4.50 \\
\hline $8 \mathrm{G}$ & -2315.84487 & -5.40 & -3.90 & 1.49141814 & 0.94 & 189.69 & 203.21 & 0.642738633 & 19 & 4.75 \\
\hline $8 \mathrm{H}$ & -2315.84642 & -5.65 & -3.57 & 2.07800261 & 0.85 & 192.08 & 205.18 & 0.640911951 & 20 & 5.00 \\
\hline AVG & -2315.85217 & -5.57 & -3.62 & 1.94177944 & 0.62 & 191.03 & 203.62 & 0.639549527 & & \\
\hline MIN & -2315.86794 & -6.06 & -3.90 & 1.49141814 & 0.00 & 189.68 & 202.88 & 0.632105836 & & \\
\hline MAX & -2315.84487 & -5.10 & -3.21 & 2.58956912 & 0.99 & 193.41 & 205.18 & 0.642738633 & & \\
\hline St.dev & 0.00853663 & 0.29 & 0.28 & 0.39848214 & 0.42 & 1.36 & 0.74 & 0.00372214178 & & \\
\hline
\end{tabular}

Table 7. Calculated numerical data in FTIR and UV-Vis spectra for isomers $\mathrm{Si}_{8}$.

\begin{tabular}{cccc}
\hline Isomer & Wavenumber of max vibration $\mathrm{cm}^{-1}$ & Wavenumber with max Intensity cm & Wavelength of the highest emission $\mathrm{nm}$ \\
\hline 8E & 508.432 & 507.490 & 535.14 \\
$8 \mathrm{~F}$ & 479.146 & 408.119 & $834.12^{*}$ \\
$8 \mathrm{~A}$ & 491.027 & 471.044 & 701.32 \\
$8 \mathrm{C}$ & 470.320 & 470.320 & 510.90 \\
$8 \mathrm{D}$ & 477.413 & 273.661 & 522.91 \\
$8 \mathrm{H}$ & 485.637 & 372.866 & 643.56 and 662.48 \\
$8 \mathrm{G}$ & 451.894 & 451.894 & 682.99 \\
$8 \mathrm{~B}$ & 452.367 & 452.367 & 595.57 \\
\hline
\end{tabular}

\footnotetext{
*There are other three energy levels in isomer $8 \mathrm{~F}$ with emissions closely respect the highest emission $(593.17,711.70 \mathrm{and} 753.90 \mathrm{~nm})$.
}

besides tetra-coordinated. In silicon bulk there is only tetra-coordinated silicon atoms. It's possible to suggest growing mechanisms for silicon nano-crystals based on coordination number. Isomers $\mathrm{Si}_{8}$ have been cited as a magic number. The "magic-number" behavior of small silicon clusters has been correlated with the trend of binding energy per atom as a function of cluster size [6]. Luo, Zhao, and Wang [7] pointed out that two factors can play major role in the cluster stability, one is the electronic configuration of an atom and another is the number of atoms in the cluster. We define the useful relationship "Coordination Average Number (CAN)" as:

$$
\mathrm{CAN}=\frac{2 \times(\text { number of } \mathrm{Si}-\mathrm{Si} \text { bonds })}{\text { Number of Silicon Atoms }}
$$

Using this definition, we can calculate for isomer $\mathrm{Si}_{8}$ CAN values in the range of 4 to 5 (refer to Table 6)

The energies calculated for isomers $\mathrm{Si}_{8}$ are included in Table 6. The energy differences regarding the isomers with lowest energy are in range from 0.16746 to 0.62787 $\mathrm{eV}$. Band Gap calculated varies between 1.49141814 and $2.58956912 \mathrm{eV}$. In this case, the isomer $8 \mathrm{E}$ shows the global minimum energy and the maximum band gap. Dipole moments are in range 0.0 to 0.99 Debye.

Statistical values for optical and geometrical parameters are listed in bottom of Table 6. In 1999 Luo et al. thought that isomer $8 \mathrm{H}$ to be the global minimum based on a semi-empirical method. The isomer $8 \mathrm{G}$, a singlycapped pentagonal bi-pyramid, was also previously thought to be the global minimum based on the tight-binding 


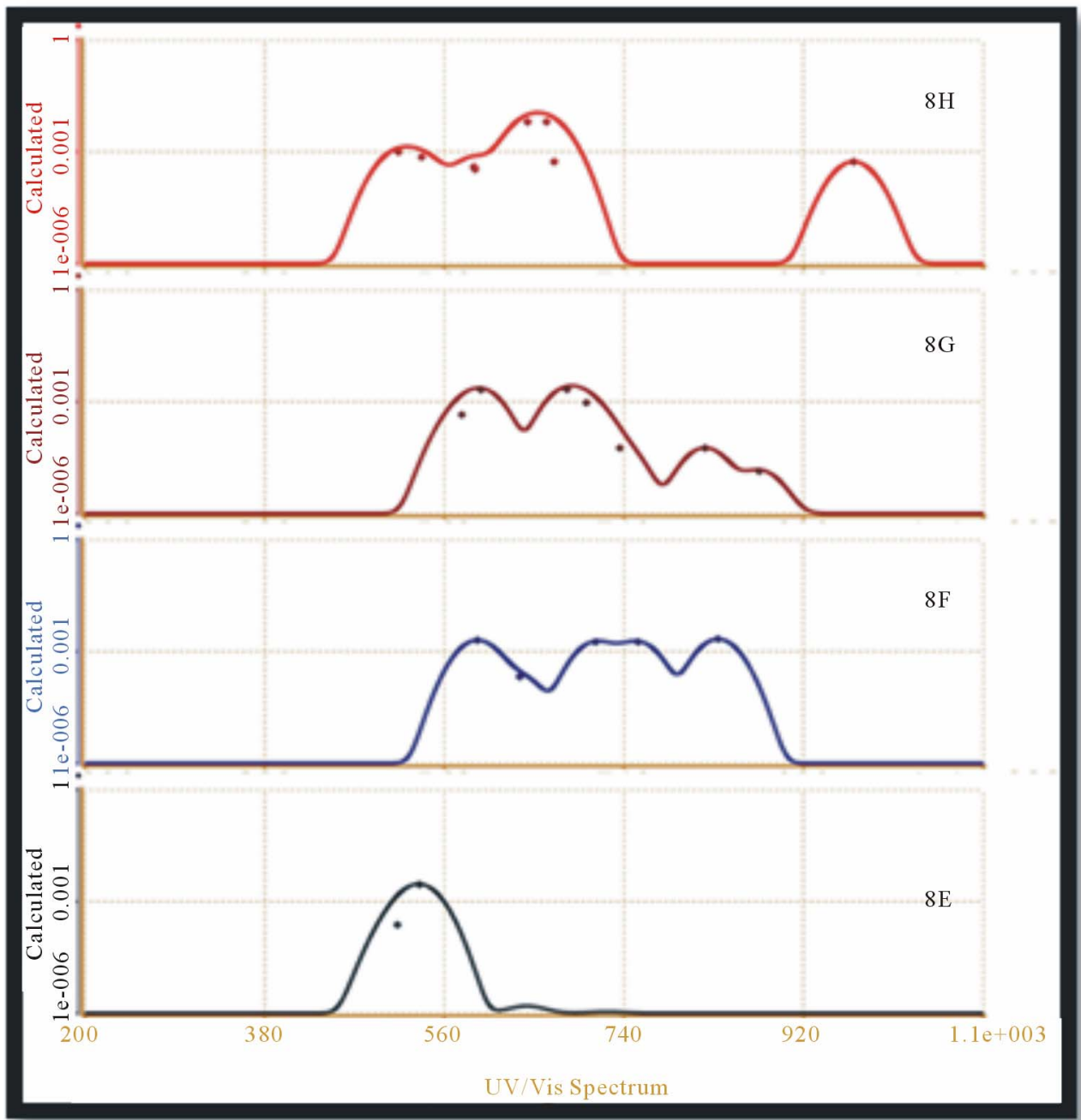

Figure 14. Calculated luminescence spectra for isomers $\mathrm{Si}_{8}$ ( $\mathrm{E}$ to $\left.\mathrm{H}\right)$.

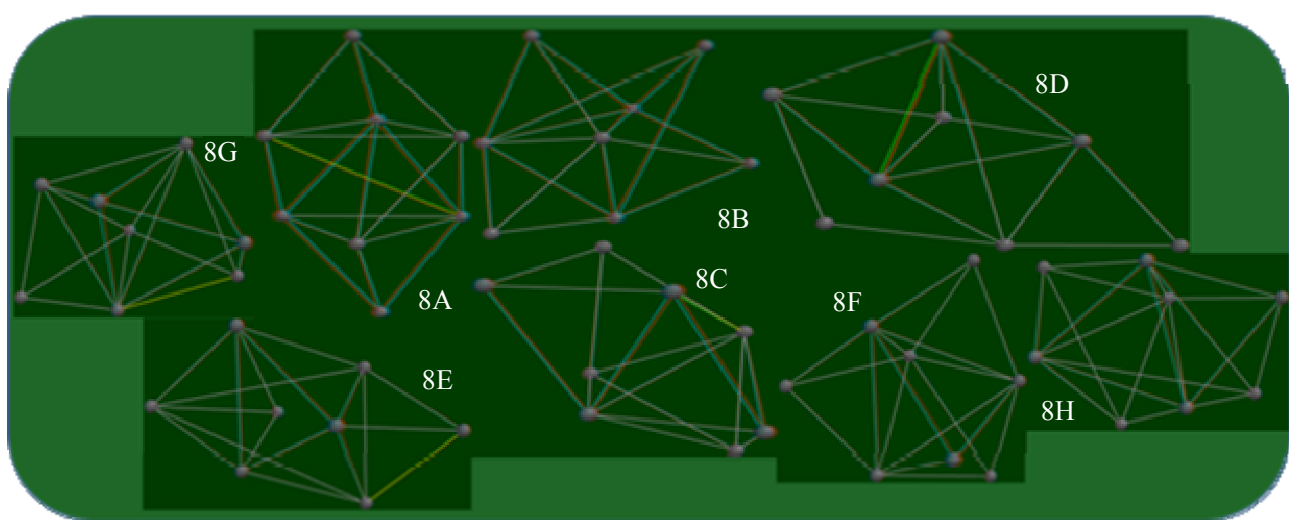

Figure 15. Agglomerate's shape and coordination isomers's $\mathrm{Si}_{8}$, using ball and wire model.

molecular dynamics calculation [37].

\subsection{Structural and Optical Properties for $\mathrm{Si}_{9}$ Isomers}

For isomers $\mathrm{Si}_{9}$, the global-minimum isomer appears to be the stacked distorted rhombi (9A) with an additional atom capped on top [38,39]. This lowest-energy structure was predicted by Vasiliev, Ogut, and Chelikowsky [40] and confirmed later by other groups $[39,41]$. It can be also viewed as a bi-capped pentagonal bi-pyramid. The isomer 
9B, also a bi-capped pentagonal bi-pyramid (but the two caps are on the same side of the pyramid), is a local minimum. In this case, we evaluated five isomers (9A to 9E) the first four as Xiaolei Zhu and X. C. Zeng [36] suggested, and additionally we evaluated the isomer 9E, and the results obtained indicate that the global-minimum energy isomer could be the isomer 9A with an energy almost equal than 9C (difference of $-6.7 * 10-6 \mathrm{au}$ ), in accordance with most of results previously reported.

The structures and FTIR spectra calculated for isomers $\mathrm{Si}_{9}$ are displayed on Figure 16. Spectra for isomers 9A and $9 \mathrm{C}$ are closely similar as expected, numerically the maximum wavenumber calculated are 480.892 and $479.594 \mathrm{~cm}^{-1}$ respectively. In a similar way, FTIR spectra for isomers $9 \mathrm{~B}$ and $9 \mathrm{E}$ are comparable with the highest vibration intensity at 392.101 and $386.835 \mathrm{~cm}^{-1}$, accordingly. Isomer 9D displays two intense peaks, at wavenumbers of 485.265 and $450.588 \mathrm{~cm}^{-1}$. Isomers $\mathrm{Si}_{9}$ have 21 freedom degree and the number of basis functions employed was 171 in a basis set 6-31G(d).

$\mathrm{UV}-\mathrm{V}$ is spectra calculated for isomers $\mathrm{Si}_{9}$ are displayed on Figure 17. Similarities discussed in FTIR spectra about isomers $9 \mathrm{~A}$ and $9 \mathrm{C}$ are found again in UV-Vis spectra. Isomers $\mathrm{Si}_{9}$ show a blue-shift respect to isomer $\mathrm{Si}_{8}$, but most of them present a maximum expected emission in green. Specifically isomer 9D displays a very wide emission since green to IR.

Quantitative information for isomers $\mathrm{Si}_{9}$ is collected in Table 8. We can say that isomers $9 \mathrm{~A}$ and $9 \mathrm{C}$ are nearly iso-energetic, they share the global minimum (relative

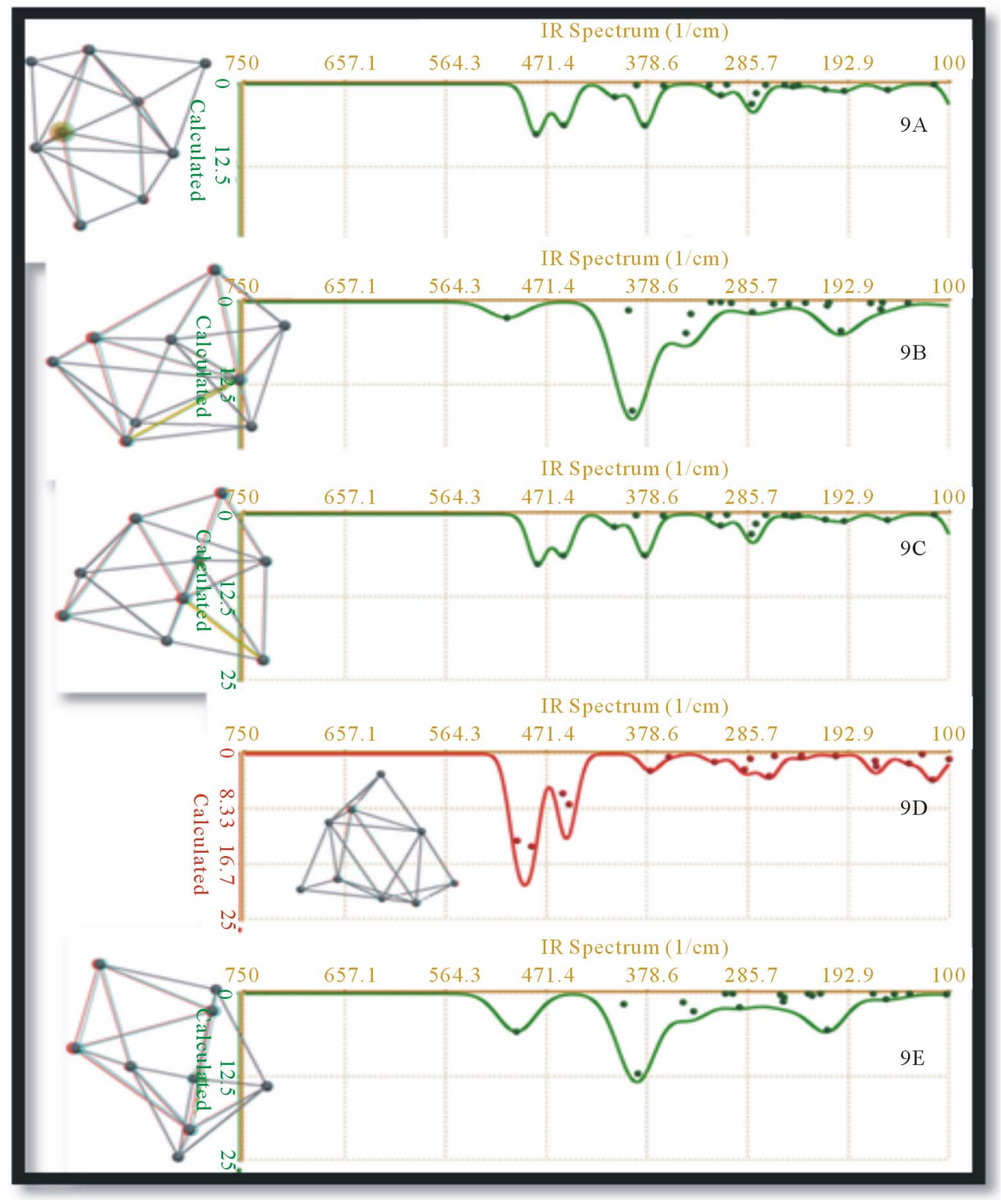

Figure 16. Structures and FTIR spectra calculated for isomers $\mathrm{Si}_{9}$. 


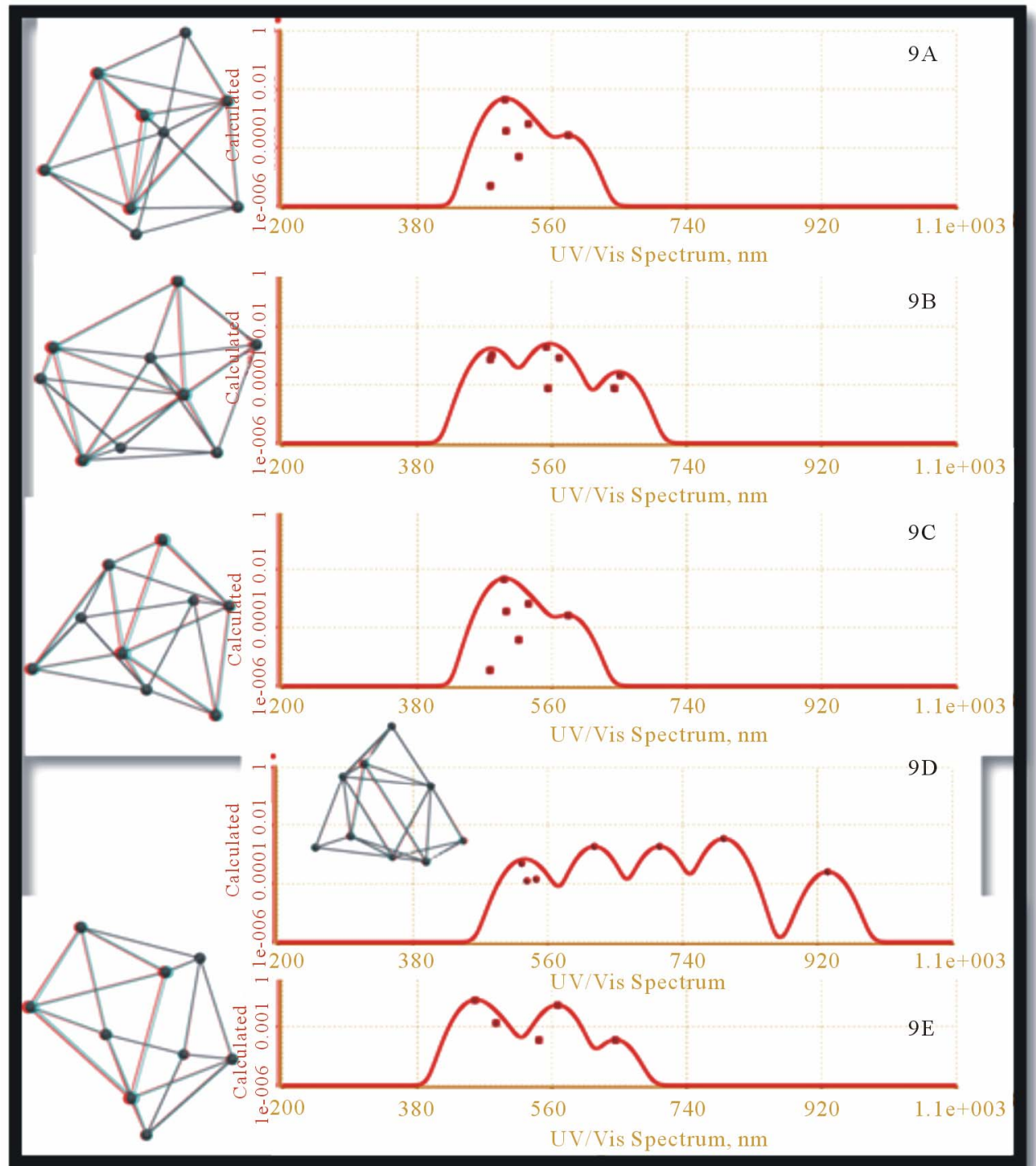

Figure 17. UV-Vis spectra calculated for isomers $\mathrm{Si}_{9}$.

Table 8. Calculated properties for isomers $\mathrm{Si}_{9}$.

\begin{tabular}{|c|c|c|c|c|c|c|c|c|}
\hline Isomer & $\begin{array}{c}\mathrm{E} \\
(\mathrm{au})\end{array}$ & $\begin{array}{l}\text { rel. E } \\
(\mathrm{eV})\end{array}$ & $\begin{array}{c}\text { Dipole } \\
\text { (debye) }\end{array}$ & $\begin{array}{c}\text { Size } \\
{[\mathrm{nm}]}\end{array}$ & ovality & polarizability & $\begin{array}{c}\text { BandGap } \\
{[\mathrm{eV}]}\end{array}$ & $\begin{array}{l}\text { Emission } \\
\max [\mathrm{nm}]\end{array}$ \\
\hline $9 \mathrm{C}$ & -2605.37750 & 0.0000 & 0.30 & 0.6584718 & 1.14282787 & 58.7832223 & 2.92214238 & 495.9544 green \\
\hline $9 \mathrm{~A}$ & -2605.37749 & 0.0002 & 0.30 & 0.6584469 & 1.14286446 & 58.7831785 & 2.92100793 & 497.0215 green \\
\hline $9 \mathrm{~B}$ & -2605.35171 & 0.7016 & 0.56 & 0.6599471 & 1.14308208 & 58.9760305 & 2.67515482 & 552.6431 green \\
\hline $9 \mathrm{E}$ & -2605.35158 & 0.7051 & 0.70 & 0.6599086 & 1.14304081 & 58.9624295 & 2.71063434 & 457.2400 blue \\
\hline 9D & -2605.3406964 & 1.0013 & 0.82 & 0.650300676 & 1.16259063 & 59.2340282 & 2.09779370 & 794.863530 \\
\hline
\end{tabular}

energy has a difference less than $10^{-2} \mathrm{eV}$ ).

\subsection{Structural and Optical Properties for Silicon Isomers $\mathrm{Si}_{10}$}

Our calculation confirms that the isomer 10A, a tetra- capped trigonal prism, is the global minimum, as already predicted by other groups $[12,13]$, and we obtain energies differences of only $0.35 \mathrm{eV}$ in respect of the global minimum for isomers $10 \mathrm{~B}, 10 \mathrm{C}$ and10D, whereas that Xiaolei et al. reported differences of 1.99 and $1.27 \mathrm{eV}$ using MP2/6-31G(d) level theory and 0.75 and $0.81 \mathrm{eV}$ 
for isomers $10 \mathrm{~B}$ and $10 \mathrm{C}$ when they apply $\mathrm{CCSD}(\mathrm{T}) /$ $6-31 \mathrm{G}(\mathrm{d})$. The isomer 10B corresponds with a tetra-capped octahedron, and is a low-energy local minimum as shown by Raghavachari and Rohlfing [6].

The isomer 10C, was obtained by B. X. Li et al. [19], via a full geometry optimization from the geometric isomer Cs.

Additionally to isomers previously reported, we include the isomer 10D. This isomer has a local minimum and its FTIR and UV-Vis spectra displayed on Figures 18 and 19 are quite closely than other similar isomers with local minimum. Quantitative differences are detailed in Table 9 where we have sorted isomers by energy column.

The band gap calculated for global minimum isomer $\mathrm{Si}_{10}(3.03117115 \mathrm{eV})$ is greater than obtained for smaller isomers $(7 \leq n \leq 9)$, and even for greater isomers like $\mathrm{Si}_{12}$. This fact attracts our attention. We should remember that $\mathrm{Si}_{10}$ is a magic-number cluster which has been extensively studied theoretically.

Maximum emission for global minimum (isomer 10A) is predicted in green region, but emission extends to blue color. Whereas, for local minimum isomers $(10 \mathrm{D}, 10 \mathrm{C}$ and 10B) the maximum expected emission includes yellow and extends until red.

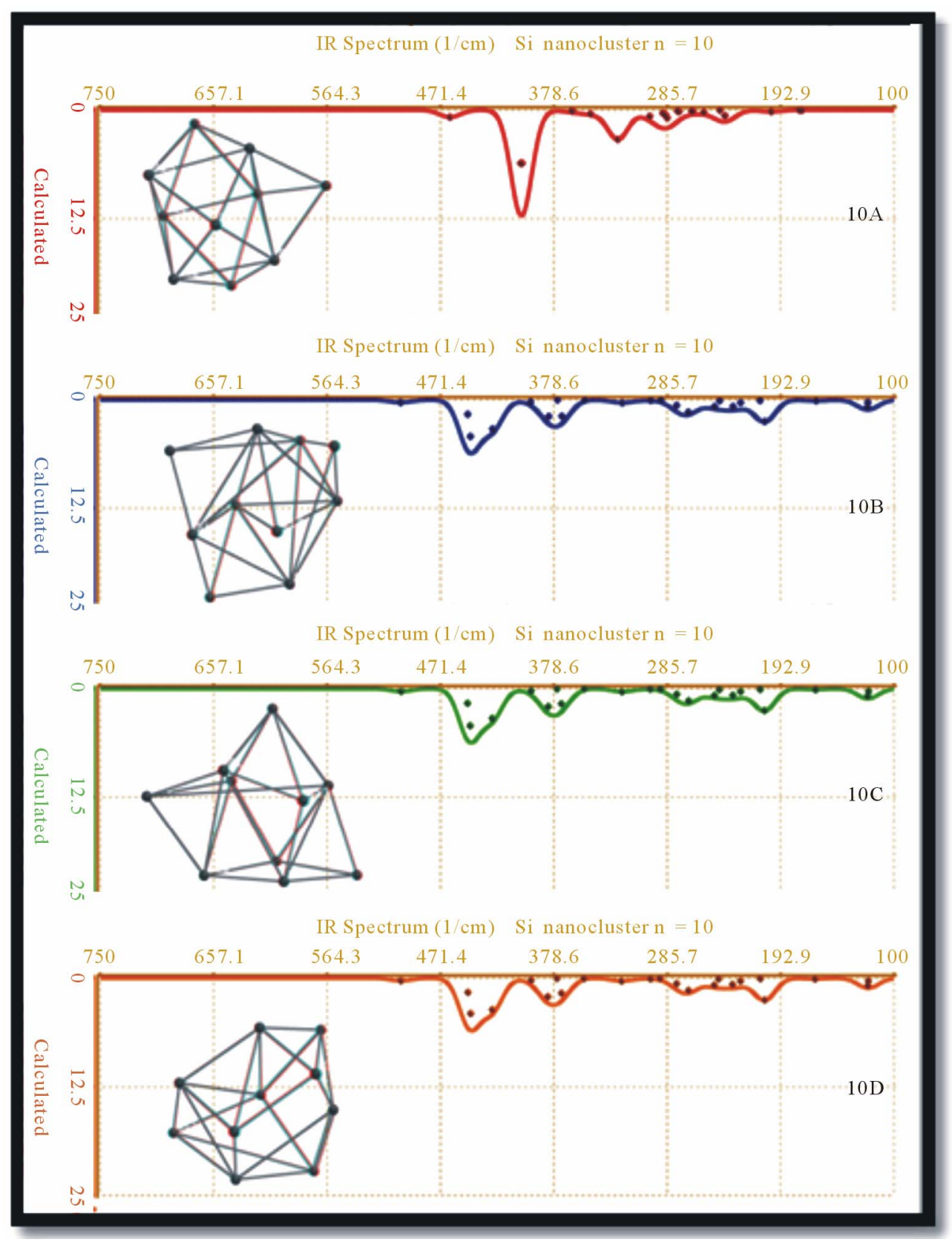

Figure 18. Structures and FTIR spectra calculated for isomers $\mathbf{S i}_{10}$. 


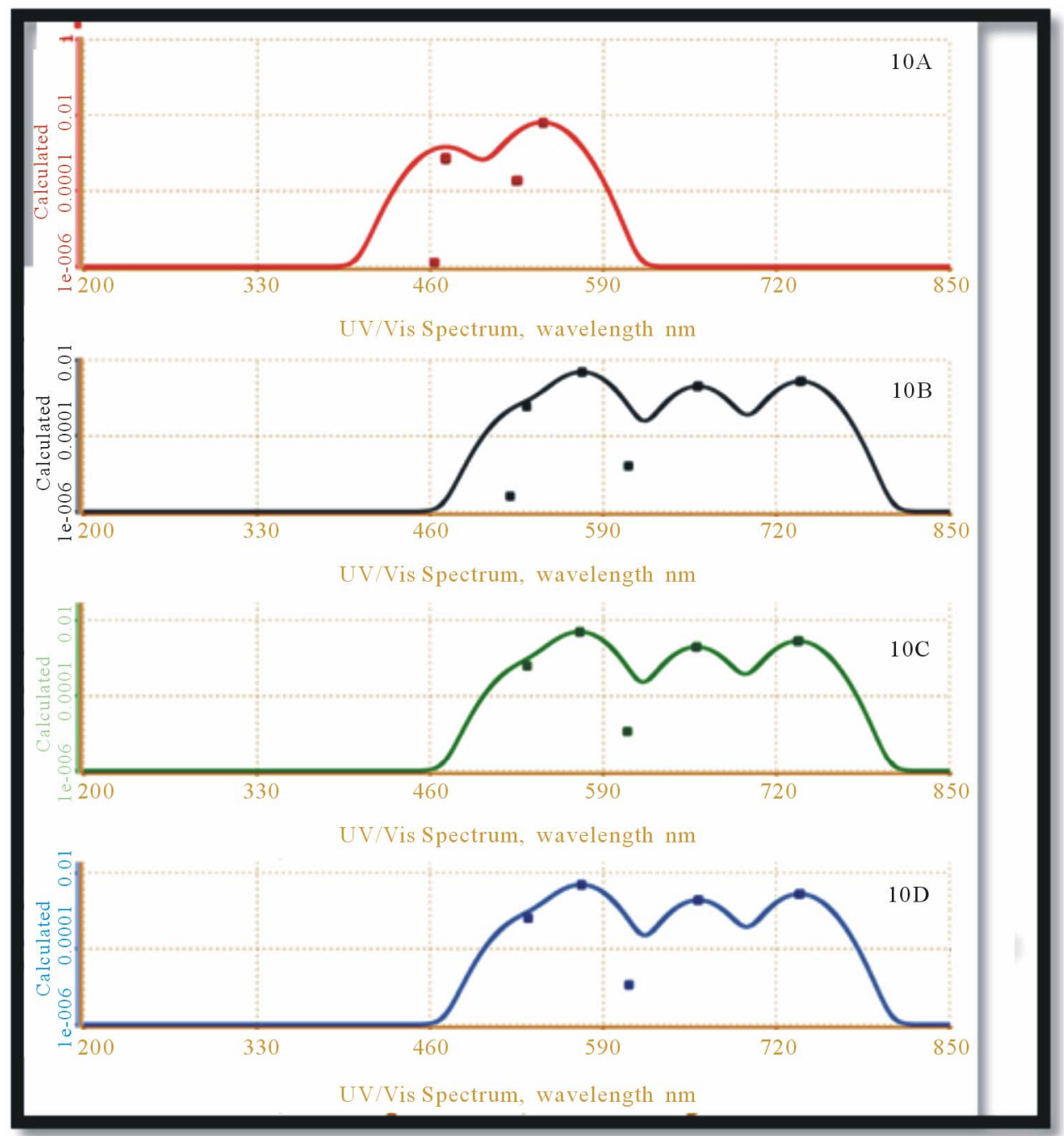

Figure 19. UV-Vis spectra calculated for isomers $\mathbf{S i}_{10}$.

Table 9. Optical and structural parameters calculated for isomers $\mathbf{S i}_{10}$.

\begin{tabular}{|c|c|c|c|c|c|c|c|c|}
\hline Isomer & $\begin{array}{l}\mathrm{E} \\
(\mathrm{au})\end{array}$ & $\begin{array}{l}\text { rel. E } \\
(\mathrm{eV})\end{array}$ & $\begin{array}{l}\text { Size } \\
{[\mathrm{nm}]}\end{array}$ & ovality & $\begin{array}{c}\text { Band Gap } \\
{[\mathrm{eV}]}\end{array}$ & Polarizability & $\begin{array}{c}\text { Emission max } \\
{[\mathrm{nm}]}\end{array}$ & $\begin{array}{c}\text { Dipole } \\
\text { [Debye] }\end{array}$ \\
\hline $10 \mathrm{~A}$ & -2894.89078 & 0.00 & 0.683933275 & 1.13152250 & 3.03117115 & 60.3433322 & 544.828431 (green) & 0.849136022 \\
\hline $10 \mathrm{D}$ & -2894.87788 & 0.35 & 0.672424038 & 1.15521041 & 2.46946364 & 60.6994128 & 573.646862 (yellow) & 0.542605980 \\
\hline $10 \mathrm{C}$ & -2894.87788 & 0.35 & 0.672457582 & 1.15510289 & 2.47251200 & 60.6961078 & 572.438798 (yellow) & 0.543559417 \\
\hline $10 \mathrm{~B}$ & -2894.87787 & 0.35 & 0.672419970 & 1.15519178 & 2.46857916 & 60.6982988 & 574.066039 (yellow) & 0.546128917 \\
\hline
\end{tabular}

\subsection{Structural and Optical Properties for Silicon Isomers $\mathbf{S i}_{11}$}

Isomer $11 \mathrm{~A}$ is a distorted tri-capped tetragonal anti-prism or a distorted penta-capped trigonal prism, isomer $11 \mathrm{~B}$ is a tri-capped trigonal prism with two additional caps on side trigonal faces, and the isomer $11 \mathrm{C}$ a bi-capped tetragonal anti-prism with an additional cap on one upper trigonal face. Among the three isomers, Lee, Chang, and Lee [37] and also later Sieck et al. [39] suggested isomer 11A as global minimum. Whereas isomers11B and 11C were predicted by Rohlfing and Raghavachari $[12,13]$ based on the HF/6-31G(d) and MP4SDQ/6-31G(d) calculations. The isomer $11 \mathrm{~B}$ was also predicted to be a possible global minimum by Ho and co-workers [16,17] using a densityfunctional pseudo-potential theory within both local density and generalized gradient approximations; 11A in Ref. $[42,43]$ was predicted to be a local minimum. Ho and 
co-workers [16,17] recently used Car-Parrinello molecular dynamics combined with the simulated annealing method to search for the global-minimumstructure of $\mathrm{Si}_{11}$. They found again that $11 \mathrm{~B}$ is most likely the global minimum. At the MP2/6-31G(d) and $\operatorname{CCSD}(\mathrm{T}) / 6-31 \mathrm{G}(\mathrm{d})$ levels, Zhu et al. [35] found that both isomers $11 \mathrm{~A}$ and $11 \mathrm{~B}$ are the possible global minimum while $11 \mathrm{C}$ is only about $0.2 \mathrm{eV}$ higher in energy than $11 \mathrm{~A}$ and $11 \mathrm{~B}$.

The isomer $11 \mathrm{D}$, another capped trigonal prism, is a new low-energy isomer whose energy is $0.52 \mathrm{eV}$ higher than that of $11 \mathrm{E}$. The newly optimized starting from $11 \mathrm{C}$ is hereafter called $11 \mathrm{E}$, which is also a capped trigonal prism. Our calculus, disclose that isomer $11 \mathrm{E}$ is the global minimum, sharing this possibility with isomer $11 \mathrm{~B}$ with an energy difference less than $10^{-3} \mathrm{eV}$ and near closely with isomer $11 \mathrm{~A}$ with only a difference of $0.23 \mathrm{eV}$. Refer to Table 10 for numerical details.

$\mathrm{Zhu}$ et al. found isomer $11 \mathrm{E}$ should be the global minimum using extended levels of theory MP2/6-311(2d) and $\operatorname{CCSD}(\mathrm{T}) / 6$ - 311(2d). Structures for isomers $\mathrm{Si}_{11}$, are displayed on inset of plots on Figure 20 (11A to 11E). Green planes are only a guide to improve view. FTIR spectra for $\mathrm{Si}_{11}$ isomers display two or three intense peaks located in intervals 470.2 - 498.4, 415.1 - 447.8 and 394.6 - $397.1 \mathrm{~cm}^{-1}$ (refer to Figure 20). One imaginary (negative) frequency for rotation was found in isomers 11A and $11 \mathrm{C}$. One imaginary frequency indicates that you are at a saddle point (transition state), which is a potential energy maximum rather than a Potential Energy Surface (PES) minimum.Negative frequencies indicate instability in the molecule or, in other words, saddle points on the potential energy surface. A stable molecule should have no imaginary frequencies, a transition state should have one (1st order saddle point), and while more than one imaginary frequency means that there is a problem with molecule's geometry.

Figure 21 displays UV-Vis spectra for isomers $\mathrm{Si}_{11}$. Calculated luminescence for isomers 11A, 11C and 11D indicates emission in visible and the most intense emission in IR region (details on Table 10). Isomer 11B will not show IR emission, only in part of visible region, with the most intense wavelength at $482.9 \mathrm{~nm}$. Whereas the global minimum (11E) displays a little bite different spectra, with partial emission in high energy levels visible region, around $523.2 \mathrm{~nm}$ and additionally emission in NIR.

\subsection{Structural and Optical Properties for Silicon Isomers $\mathrm{Si}_{13}$}

The Jahn-Teller effect (JTE), sometimes also known as Jahn-Teller distortion, describes the geometrical distortion of molecules associated with certain electron configurations. JTE proved, using group theory, that orbital nonlinear spatially degenerate molecules cannot be stable [44]. The effect essentially states that any nonlinear molecule with a spatially degenerate electronic ground state will undergo a geometrical distortion that removes that degeneracy, because the distortion lowers the overall energy of the species. Another type of geometrical distortion occurs in crystals with substitutional impurities (off-center ions). The Jahn-Teller effect is manifested in the UV-VIS absorbance spectra of some compounds, where it often causes splitting of bands. Many theoretical studies have been devoted to the $\mathrm{Si}_{13}$ cluster because of the possibility of finding a high-symmetry (Ih) core-based icosahedral structure [40]. It was later shown that the high-symmetry icosahedral cluster is unstable due to the Jahn-Teller distortion [45].

Using a quantum Monte Carlo method, Grossman and Mitas [46] investigated several isomers of $\mathrm{Si}_{13}$ and found that the $\mathrm{C} 3 \mathrm{v}$ trigonal anti-prism isomer $13 \mathrm{~B}$ is more stable than the core-based icosahedral $\mathrm{Si}_{13}(\mathrm{Ih})$. Here, we confirm that isomer 13A has the global minimum and there are two isomers (13B and 13D) near iso-energetic with only a difference of $0.20 \mathrm{eV}$.

FTIR spectra calculated for isomers $\mathrm{Si}_{13}$ are displayed on Figure 22. Note that we increase scale of intensity (0 40 U.A.) mainly due to that isomer $13 \mathrm{C}$ results with relative high intensity at frequencies of $360.282,471.024$ and $499.159 \mathrm{~cm}^{-1}$. Isomers $\mathrm{Si}_{13}$ exhibit 33 freedom degrees and employ 247 basis functions.

All isomers $\mathrm{Si}_{13}$ are supra-coordinated (CAN in range from $56 / 13$ for isomer $13 \mathrm{~B}$ to $66 / 13$ for isomer $13 \mathrm{E}$ ).

Calculated zero point vibration energy (ZPVE) resulted near of $0.5 \mathrm{eV}$ (see Table 11).

Except for isomer $13 \mathrm{E}$, most of $\mathrm{Si}_{13}$ isomers have high

Table 10. Optical and structural parameters calculated for isomers $\mathrm{Si}_{11}$.

\begin{tabular}{|c|c|c|c|c|c|c|c|c|c|}
\hline Isomer & $\begin{array}{c}\text { Energy } \\
{[\text { Hartree] }}\end{array}$ & $\begin{array}{l}\text { Size } \\
{[\mathrm{nm}]}\end{array}$ & $\begin{array}{c}\text { rel. E } \\
(\mathrm{eV})\end{array}$ & $\begin{array}{c}\text { BandGap } \\
{[\mathrm{eV}]}\end{array}$ & Ovality & Polarizability & $\begin{array}{c}\text { UV-Vis lambda } \\
\max [\mathrm{nm}]\end{array}$ & $\begin{array}{c}\text { ZPVE } \\
{[\mathrm{eV}]}\end{array}$ & $\begin{array}{c}\text { Dipole } \\
\text { [Debye] }\end{array}$ \\
\hline $11 \mathrm{E}$ & -3184.35805 & 0.693056173 & 0.00 & 2.19509315 & 1.15150032 & 62.4448440 & 523.201425 & 0.45 & 1.24 \\
\hline $11 \mathrm{~B}$ & -3184.35756 & 0.677192371 & 0.00 & 2.80085581 & 1.15805475 & 62.1385317 & 482.900429 & 0.46 & 1.42 \\
\hline $11 \mathrm{~A}$ & -3184.34961 & 0.695816933 & 0.23 & 2.10033143 & 1.14506899 & 62.3623936 & 845.486195 & 0.44 & 0.85 \\
\hline $11 \mathrm{C}$ & -3184.34615 & 0.698294535 & 0.32 & 2.21935306 & 1.14334264 & 62.4663103 & 743.763218 & 0.43 & 1.58 \\
\hline $11 \mathrm{D}$ & -3184.3373902 & 0.678075916 & 0.52 & 1.93414927 & 1.15876761 & 62.4122287 & 959.659273 & 0.44 & 0.70 \\
\hline
\end{tabular}




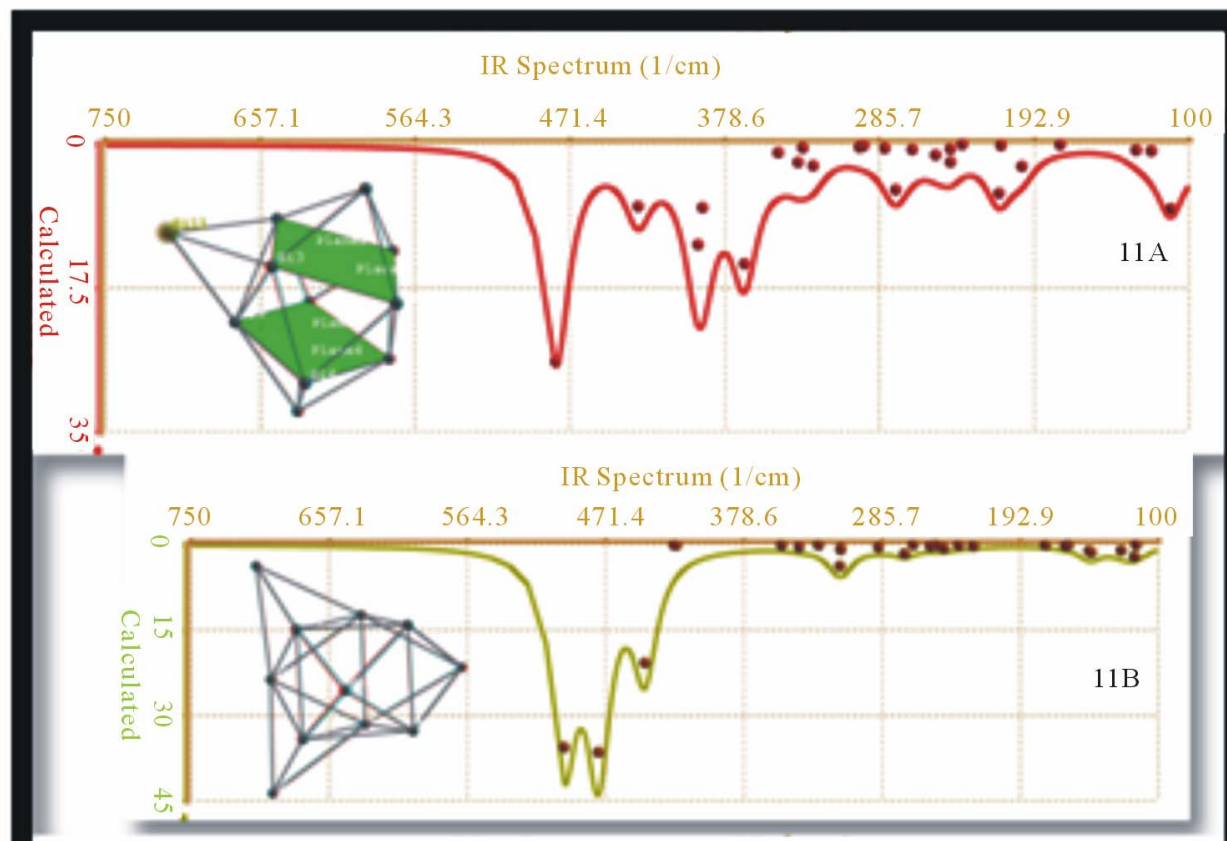

IR Spectrum $(1 / \mathrm{cm})$

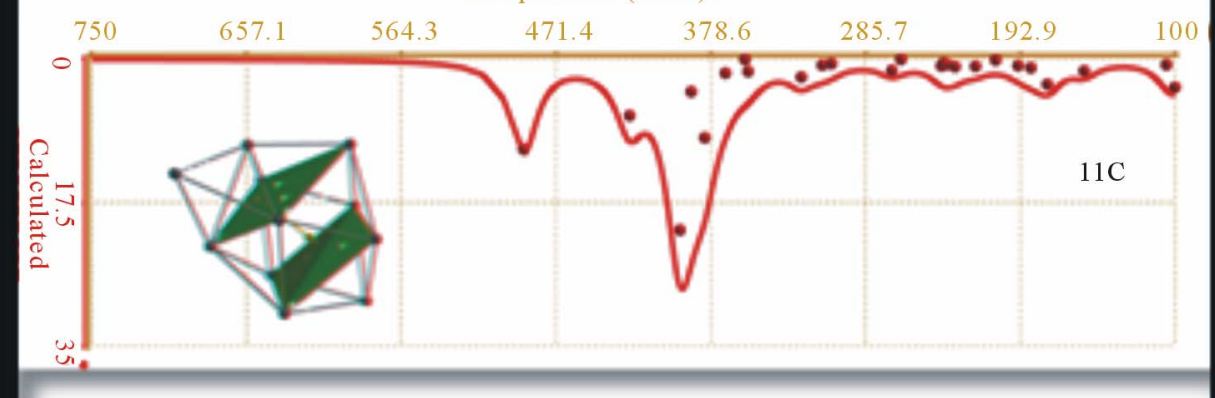

IR Spectrum $(1 / \mathrm{cm})$

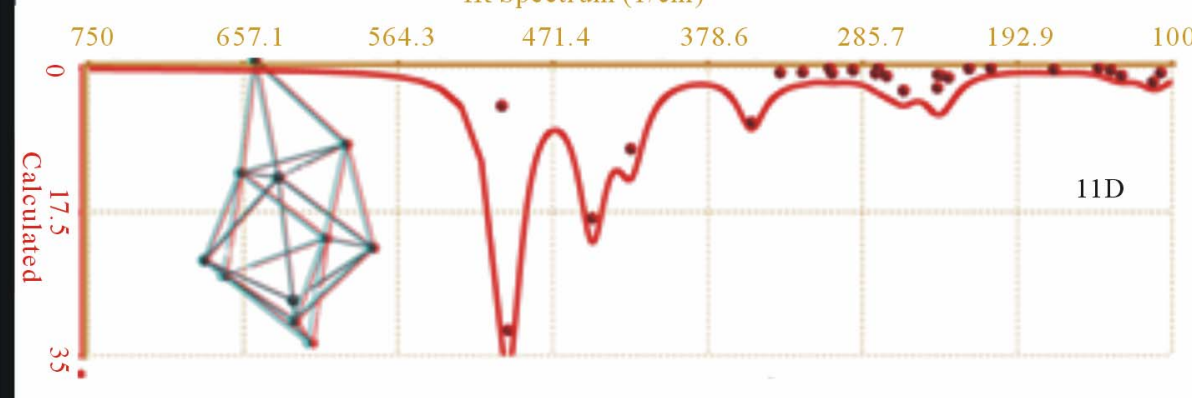

IR Spectrum $(1 / \mathrm{cm})$

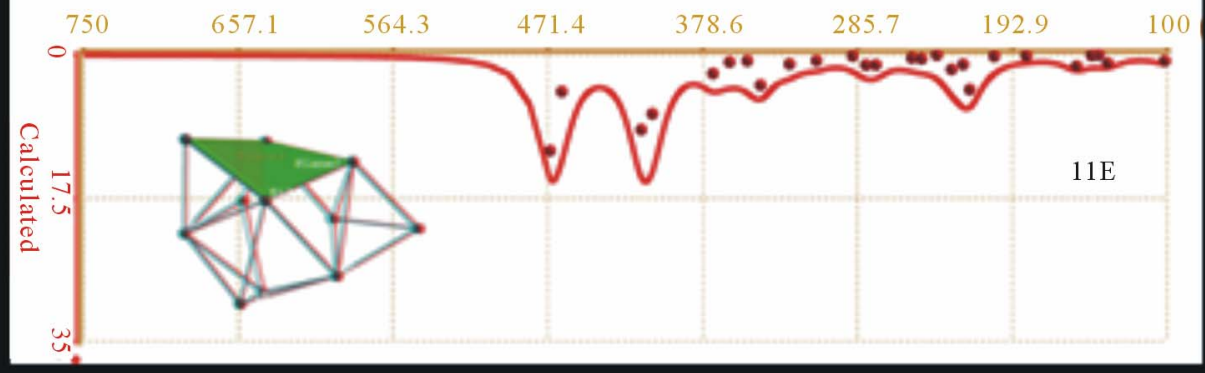

Figure 20. Structures and FTIR spectra calculated for isomers $\mathrm{Si}_{11}$. 


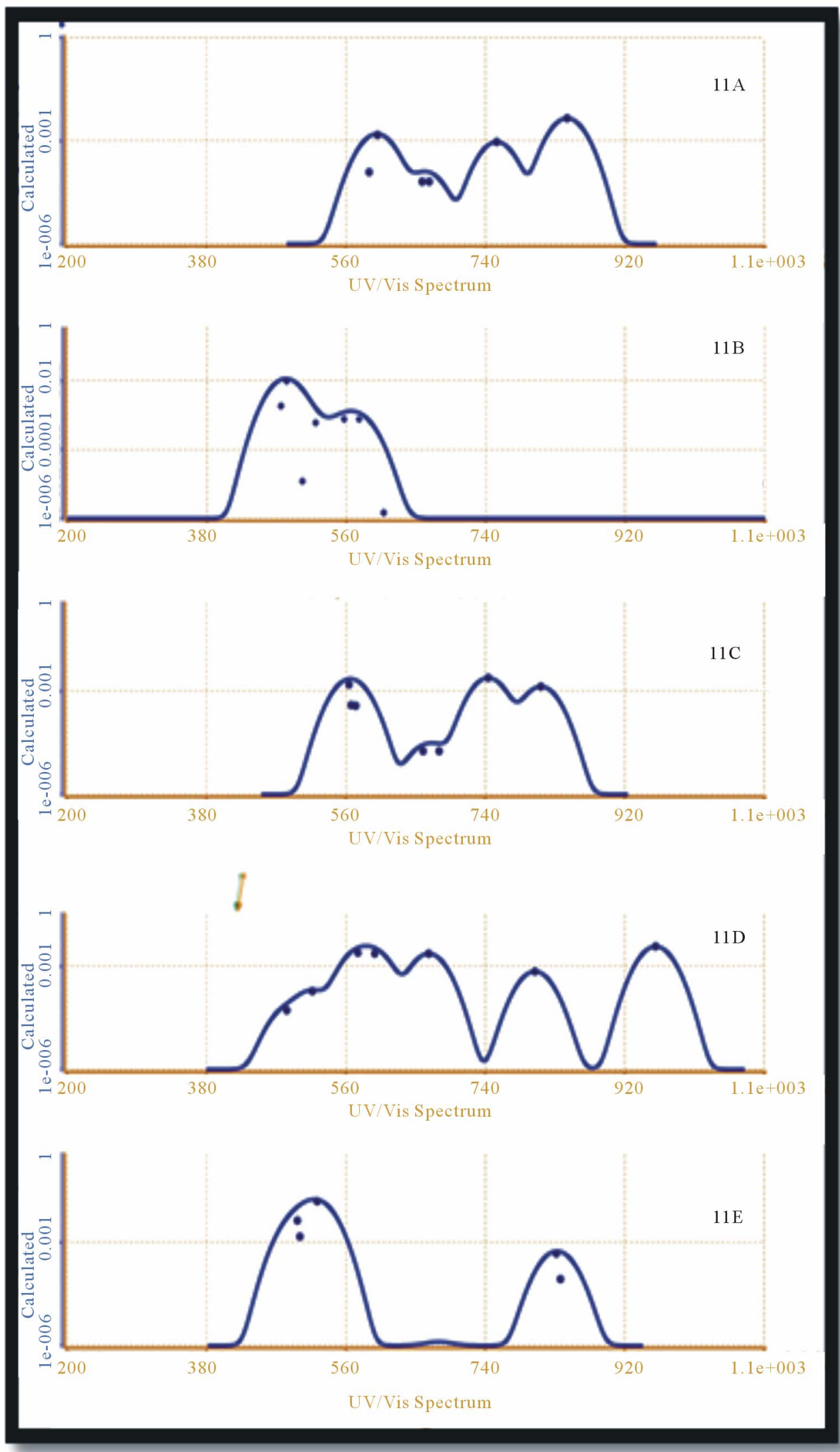

Figure 21. UV-Vis spectra calculated for isomers $\mathbf{S i}_{11}$. 


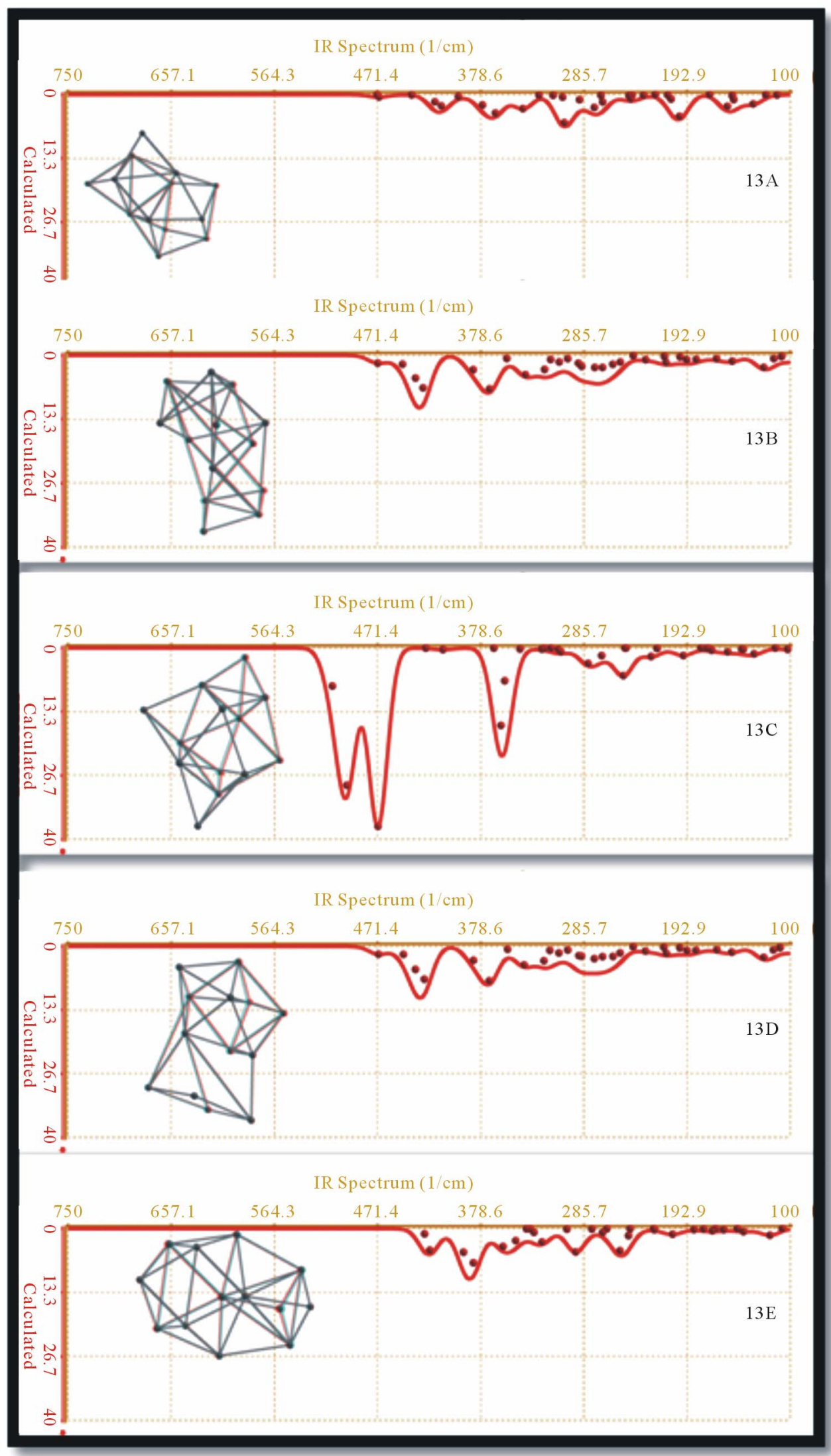

Figure 22. Structures and FTIR spectra calculated for isomers $\mathrm{Si}_{13}$ (13A to $13 E$ ). 
Table 11. Optical and structural parameters calculated for isomers $\mathrm{Si}_{13}$.

\begin{tabular}{|c|c|c|c|c|c|c|c|c|c|}
\hline Isomer & $\begin{array}{c}\text { Energy } \\
\text { [Hartree] }\end{array}$ & $\begin{array}{l}\text { Size } \\
{[\mathrm{nm}]}\end{array}$ & $\begin{array}{l}\text { rel. E } \\
(\mathrm{eV})\end{array}$ & $\begin{array}{c}\text { BandGap } \\
{[\mathrm{eV}]}\end{array}$ & Ovality & Polarizability & $\begin{array}{l}\text { UV-Vis_lambda } \\
\max [\mathrm{nm}]\end{array}$ & $\begin{array}{c}\text { ZPVE } \\
{[\mathrm{eV}]}\end{array}$ & $\begin{array}{c}\text { Dipole } \\
\text { [Debye] }\end{array}$ \\
\hline $13 \mathrm{~A}$ & -3763.34 & 0.717113835 & 0.00 & 1.85408440 & 1.16867826 & 65.9397550 & 1040.06464 & 0.552653862 & 1.75427983 \\
\hline $13 \mathrm{~B}$ & -3763.33 & 0.706346662 & 0.20 & 2.04189784 & 1.19298239 & 66.3075238 & 831.133765 & 0.526377920 & 1.33654866 \\
\hline $13 \mathrm{D}$ & -3763.33 & 0.706292353 & 0.20 & 2.04096395 & 1.19302900 & 66.3048626 & 832.318003 & 0.526413642 & 1.34921474 \\
\hline $13 \mathrm{E}$ & -3763.32 & 0.715329781 & 0.37 & 1.76424755 & 1.17746253 & 66.3388454 & 676.653707 & 0.514426303 & 0.637141338 \\
\hline $13 \mathrm{C}$ & -3763.32 & 0.711660333 & 0.39 & 2.23694992 & 1.18132246 & 66.0842505 & 563.351931 & 0.545898936 & 1.78208642 \\
\hline
\end{tabular}

dipole moment values (greater than 1.3 Debye). Average size of isomers $\mathrm{Si}_{13}$ is $0.71134 \mathrm{~nm}$. Band gap average calculated over five isomers is $1.9876 \mathrm{eV}$. We can appreciate structural shapes in left inset $13 \mathrm{~A}$ to $13 \mathrm{E}$ of Figure 22.

Calculated luminescence for isomers $\mathrm{Si}_{13}$ is shown on Figure 23. For isomer 13A, the spectra calculated include two main peaks, one with emission in visible region (red) and another with the highest emission intensity in NIR (1040.064 $\left.\mathrm{cm}^{-1}\right)$.

On both sides of the peaks there are shoulders with similar intensities, at $670.75 \mathrm{~nm}$ and $1098.66 \mathrm{~nm}$, respectively. Isomers $13 \mathrm{~B}$ and $13 \mathrm{D}$ are iso-energetic, and for this reason their UV-Vis spectra are quite similar. To appreciate numerical differences see Table 11.

As we have said already, isomer 13C has the highest vibrations intensity and its luminescence spectra content two symmetric peaks. The highest local minimum corresponds to isomer $13 \mathrm{C}$. Also, isomer $13 \mathrm{C}$ results with the highest band gap (2.237 eV) and dipole moment calculated (1.782 Debye). Whereas that, the isomer 13E has the lowest band gap, ZPVE and dipole moment, and the emission in IR trends to disappear.

\subsection{Structural and Optical Properties for Silicon Isomers $\mathrm{Si}_{14}$}

For $\mathrm{Si}_{14}$ clusters, a number of low-lying isomers have been cited in the literature $[16,17,37,39,47-50]$. Isomer $14 \mathrm{~A}\left(\mathrm{C}_{\mathrm{s}}\right)$ has two stacked rhombi with distortion and one five-fold ring capped with an atom. The vibrational frequency analysis done by Zhu et al. [15] indicates isomer 14A has one imaginary frequency. Ours results to not contain a transition state for this isomer. A structural perturbation followed by geometry relaxation gives isomer $14 \mathrm{~A}$ bis $\left(\mathrm{C}_{1}\right)$ which is very close in structure to $14 \mathrm{~A}$. $14 \mathrm{~A}$ bis also exhibits a stacking sequence of two distorted rhombi, one five-fold ring, and an atom on top. General agreement is that the isomer 14A $\left(\mathrm{C}_{\mathrm{s}}\right)$ found by Sieck et al. [39] is possibly the global minimum. Ours calculus confirm isomer $14 \mathrm{~A}$ as global minimum (see Table 12) sharing the possibility to be global minimum with isomer $14 \mathrm{~A}$ bis with an energy difference of only $-0.00009 \mathrm{eV}$.
Isomers 14B, 14C, and 14D all exhibit a stacking sequence of three (distorted) rhombi with one atom at the top and another at the bottom. The vibrational frequency analysis indicates that isomer 14D has one imaginary frequency, it means that, this isomer is a transition state. Isomer 14E has a capped trigonal-prism unit and we obtain two imaginary frequencies for this isomer. Structures for isomers $\mathrm{Si}_{14}$ are included on insets Figures 24 and 25. Energy differences calculated for isomers $14 \mathrm{~A}$ bis to $14 \mathrm{E}$, respect to isomer 14A, are much higher than $0.4 \mathrm{eV}$.

There are 36 freedom degrees for isomers $\mathrm{Si}_{14}$. Isomers with global minimum (14A and 14A bis) have the lowest vibration intensities, whereas isomer 14D which results to be a transition state, has the highest vibration intensity which corresponds to $393.601 \mathrm{~cm}^{-1}$.

The highest emission expected for isomer 14A corresponds with green color $(509.249 \mathrm{~nm})$ and is quite similar to expected for isomer 14A bis $(509.263 \mathrm{~nm})$. Most of their properties are similar except may be the size. This pair of isomers will emit in a wide band from violet to green. Isomers $14 \mathrm{~B}$ and $14 \mathrm{C}$ show a redshift and extend covering a great part of visible region, isomer $14 \mathrm{D}$ does not display detectable emission and isomer 14E will emit preferably in NIR.

\section{Conclusions}

We have calculated low-energy nano-structures of $\mathrm{Si}_{7}-$ $\mathrm{Si}_{14}$ at the HF/6-31G(d) level of theory. The vibrational frequency analysis has been used to confirm the stability of the lowest-energy structures of $\mathrm{Si}_{7}-\mathrm{Si}_{14}$ isomers. We employed FTIR calculated spectra in order to identify silicon agglomerates found in SRO film deposited by LPCVD. We evaluated different local energy isomers and we obtained the global isomers $\mathrm{Si}_{7}-\mathrm{Si}_{14}$ (lowest-energy), and found energy differences less than $0.5 \mathrm{eV}$ for most of isomers evaluated, except for $\mathrm{Si}_{14}$ in which the differences in energy are bigger. By plotting the binding energy per atom as a function of $\mathrm{n}^{-1 / 3}$ where $\mathrm{n}$ is the cluster size, for small agglomerates $\left(\mathrm{Si}_{7}-\mathrm{Si}_{11}\right)$, the binding energy per atom has an $n^{-1 / 3}$ dependence, suggesting that small silicon clusters trends spherical-like cluster growth. Haberland proposed that the deviation from the linear behavior 


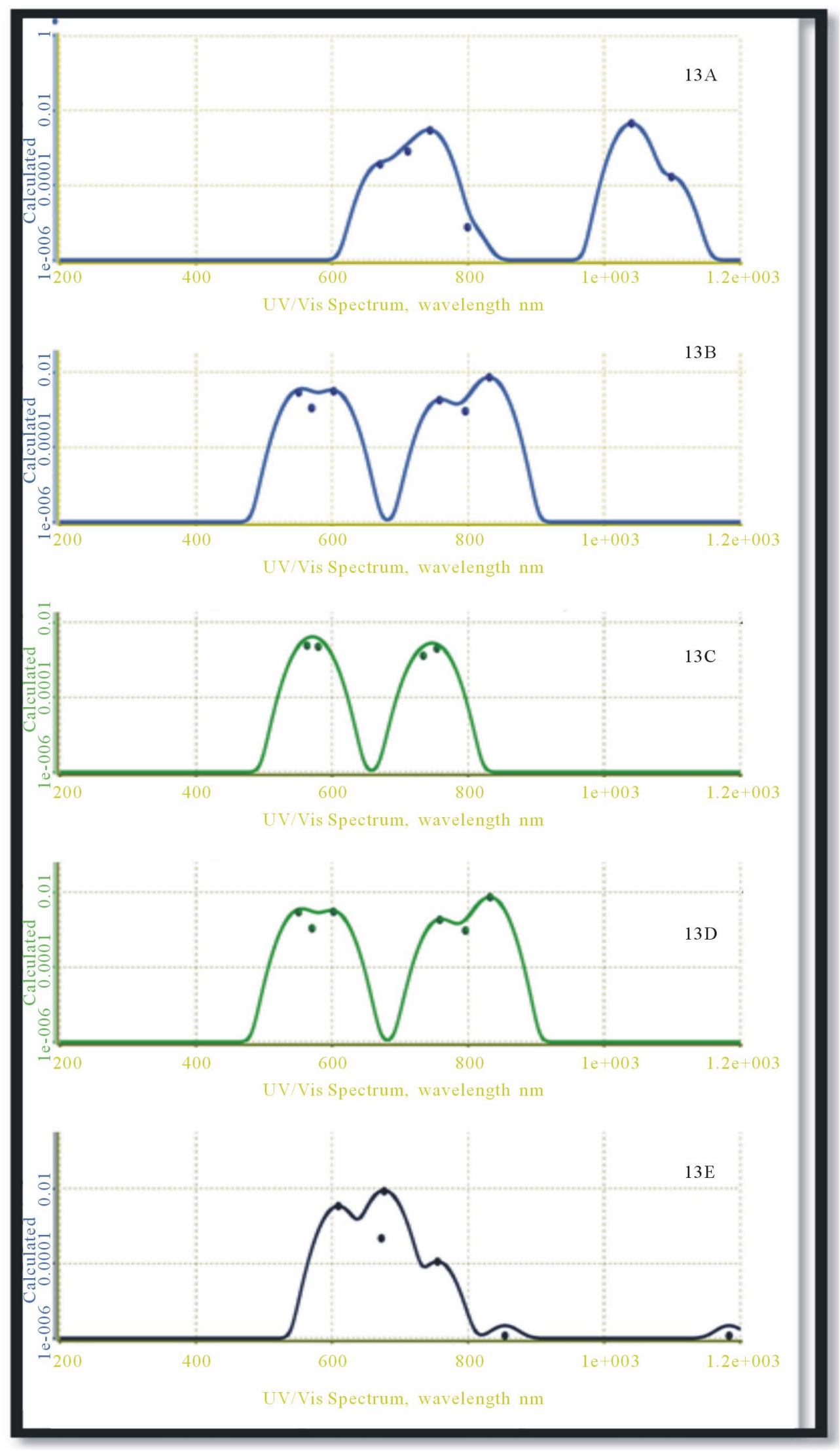

Figure 23. UV-Vis spectra calculated for isomers $\mathrm{Si}_{13}$ (13A to 13E). 
Table 12. Optical and structural parameters calculated for isomers $\mathrm{Si}_{14}$.

\begin{tabular}{ccccccccc|}
\hline Isomer & $\mathrm{E}(\mathrm{au})$ & rel. E $(\mathrm{eV})$ & Size[nm] & BandGap eV & Ovality & Polarizability & Dipole (debye) & UVVIS_LAMDA UAX $^{\prime}$ \\
\hline 14A & -4052.84522 & 0.00000 & 0.7266395 & 2.749521 & 1.182271 & 67.65458 & 1.434 & 509.249 \\
14A BIS & -4052.84522 & -0.00009 & 0.7184460 & 2.749496 & 1.182271 & 67.65463 & 1.434 & 509.263 \\
14B & -4052.81350 & 0.86313 & 0.7223203 & 2.172161 & 1.189517 & 67.80396 & 3.119 & 669.498 \\
14C & -4052.83006 & 0.41248 & 0.7125147 & 2.330958 & 1.212384 & 68.20395 & 0.647 & 565.667 \\
14D & -4052.77424 & 1.93145 & 0.7382580 & 1.792246 & 1.164919 & 67.96963 & 0.002 & Non detectable emission \\
14E & -4052.75299 & 2.50957 & 0.7145326 & 1.112898 & 1.205495 & 68.25954 & 1.436 & 958.566 \\
\hline
\end{tabular}

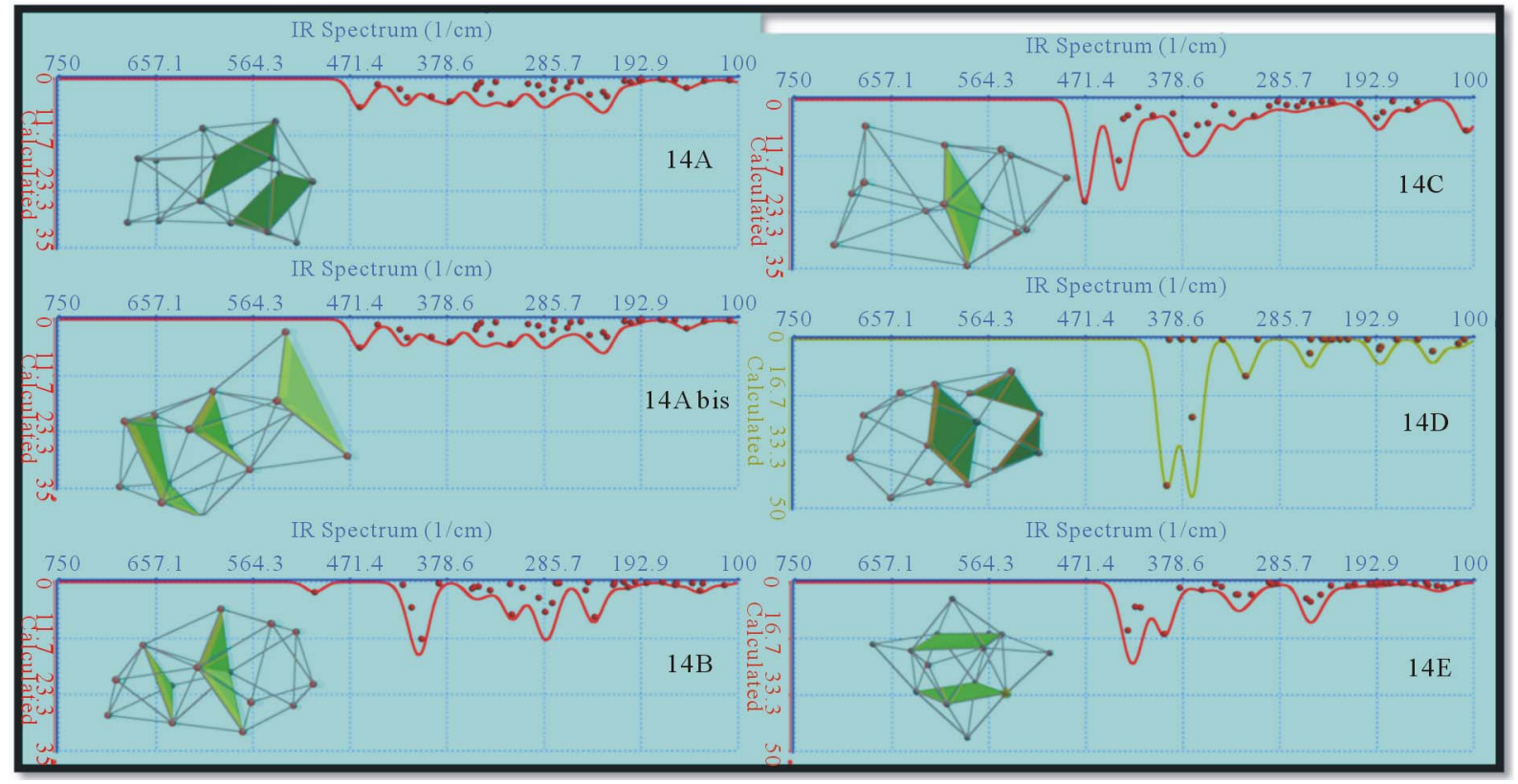

Figure 24. Structures and FTIR spectra calculated for isomers $\mathrm{Si}_{14}$. Isomer $14 \mathrm{D}$ with the highest frequency intensity, scale $\mathrm{O}$ 50 (u.a.) for isomers 14D and 14E.

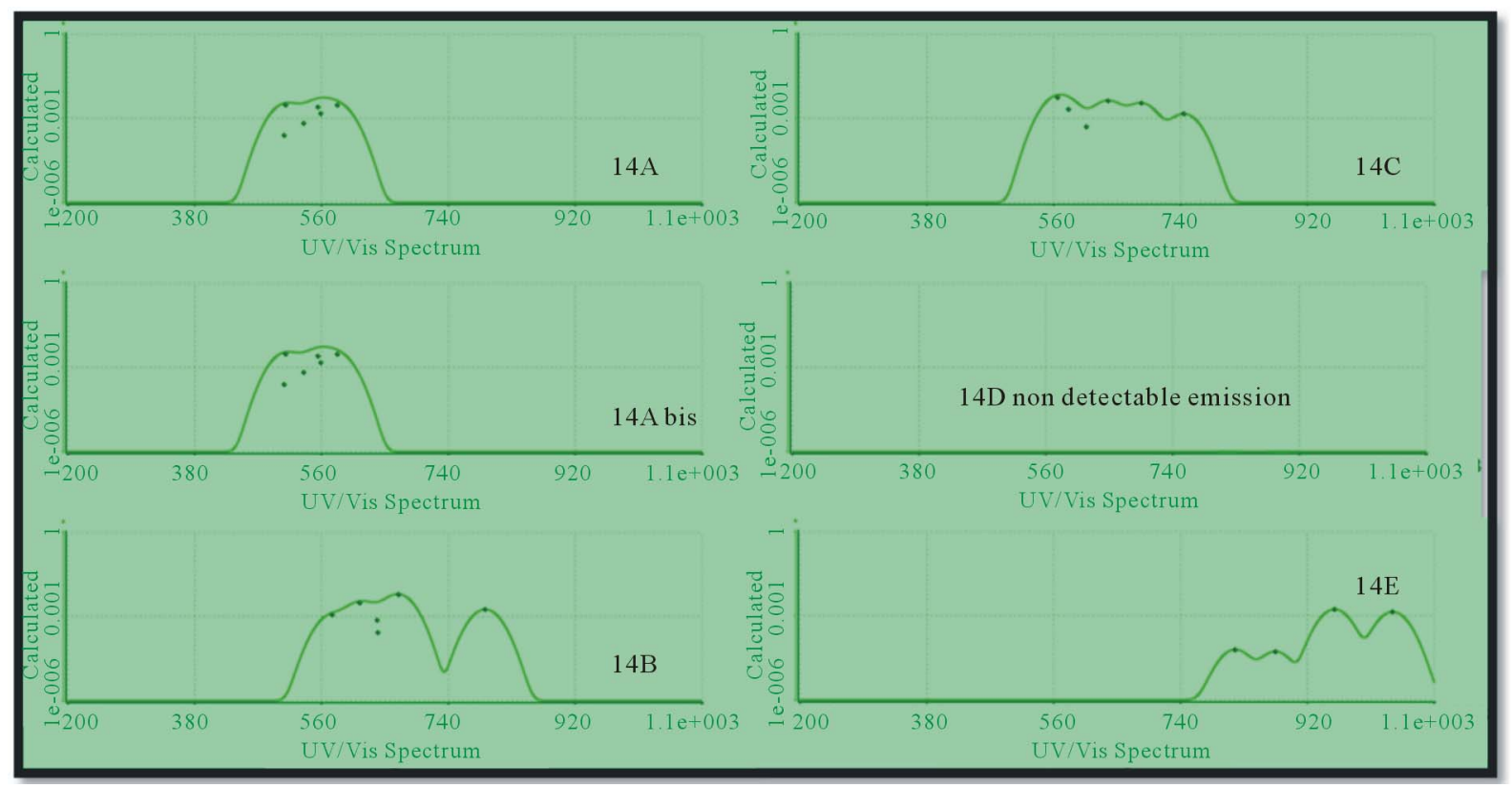

Figure 25. UV-Vis spectra calculated for isomers $\mathrm{Si}_{14}$. Isomer $14 \mathrm{D}$ has not detectable emission. 
for the binding energy versus $\mathrm{n}^{-1 / 3}$ curve suggests the growth pattern of the low-lying medium-sized $\left(\mathrm{Si}_{12}-\mathrm{Si}_{14}\right)$ clusters deviates from the spherical growth pattern [50]. This fact indicates that the low-lying $\mathrm{Si}_{7}-\mathrm{Si}_{14}$ clusters follow a non-spherical growth pattern. Also, we note that the lowest-energy structures of $\mathrm{Si}_{12}-\mathrm{Si}_{14}$ all contain the TTP $\mathrm{Si}_{9}$ unit. Although the TTP $\mathrm{Si}_{9}$ unit is not a standalone local minimum, it appears to be a favorable building block [38] for medium-sized clusters $\mathrm{Si}_{12}-\mathrm{Si}_{14}$.

We calculated UV-Vis spectra for isomers $\mathrm{Si}_{7}-\mathrm{Si}_{14}$. We found that most of the silicon agglomerates with small and medium size (less than $1.0 \mathrm{~nm}$ ) could emit in visible region and this is a transcendental fact; because up to now, it is not possible to detect experimentally nanoagglomerates with size less than $1.0 \mathrm{~nm}$ and could be an explantion for finding luminescence in SRO thin films with Ro $=30$.

\section{Acknowledgements}

This work has been partially supported by CONACyT-154725, PIFI-2013 and VIEP-BUAP-2013. N.D. Espinosa-Torres acknowledges the financial support of CONACYT by the scholarship given to carry out $\mathrm{PhD}$ studies, to VIEP and ICUAP-CIDS for support through PIFI 2012 projects and gives a special acknowledgment to the Academic Team: "Organic and Nano-structured Semiconductors" for their invaluable support.

\section{REFERENCES}

[1] L. T. Canham, Applied Physics Letters, Vol. 57, 1990, p. 1046. http://dx.doi.org/10.1063/1.103561

[2] D. J. Lockwood, "Light Emission in Silicon," In: D. J. Lockwood, Ed., Light Emission in Silicon from Physics to Devices. Semiconductors and Semimetales, Vol. 49, Academic Press, San Diego, 1998.

[3] Z. Z. Yuan, G. Pucker, A. Marconi, F. Sgrignuoli, A. Anopchenko, Y. Jestin, L. Ferrario, P. Bellutti and L. Pavesi, Solar Energy Materials and Solar Cells, Vol. 95, 2011, pp. 1224-1227. http://dx.doi.org/10.1016/j.solmat.2010.10.035

[4] N. D. Espinosa-Torres, J. F. J. Flores-Gracia, J. A. LunaLópez, A. Morales-Sánchez, Ragnar Kiebach, J. C. Ramírez-García, D. Hernández de la Luz and E. CamachoEspinosa. "In Silico Study of Electro-Luminescence in SRO thin Films due to $\left[\mathrm{Si}_{\mathrm{n}}-\mathrm{O}_{\mathrm{n}}\right]$," Will be Published.

[5] W. D. Knight, K. Clemenger, W. A. de Heer, W. A. Saunders, M. Y. Chou and M. L. Cohen, Physical Review Letters, Vol. 52, 1984, pp. 2141-2143. http://dx.doi.org/10.1103/PhysRevLett.52.2141

[6] K. Raghavachari and C. M. Rohlfing, The Journal of Chemical Physics, Vol. 89, 1988, p. 2219. http://dx.doi.org/10.1063/1.455065

[7] Y. H. Luo, J. J. Zhao and G. H. Wang, Physical Review B, Vol. 60, 1999, pp. 10703-10706. http://dx.doi.org/10.1103/PhysRevB.60.10703
[8] D. E. Bergeron and A. W. Castleman Jr., The Journal of Chemical Physics, Vol. 117, 2002, p. 3219.

http://dx.doi.org/10.1063/1.1486439

[9] S. Yoo, X. C. Zeng, X. Zhu and J. Bai, Journal of American Chemical Society, Vol. 125, 2003, pp. 13316-13317. http://dx.doi.org/10.1063/1.1690755

[10] M. V. Ramakrishna and A. Bahel, The Journal of Chemical Physics, Vol. 104, 1996, p. 9833. http://dx.doi.org/10.1063/1.471742

[11] A. Bahel and M. V. Ramakrishna, Physical Review B, Vol. 51, 1995, pp. 13849-13851. http://dx.doi.org/10.1103/PhysRevB.51.13849

[12] Rohlfing and K. Raghavachari, Chemical Physics Letters, Vol. 198, 1990, p. 521.

[13] C. M. Rohlfing and K. Raghavachari, Chemical Physics Letters, Vol. 198, 1992, p. 521.

[14] Z. Y. Lu, C. Z. Wang and K. M. Ho, Physical Review B, Vol. 61, 2000, pp. 2329-2334. http://dx.doi.org/10.1103/PhysRevB.61.2329

[15] X. Zhu and X. C. Zeng, The Journal of Chemical Physics, Vol. 118, 2003, p. 3558. http://dx.doi.org/10.1063/1.1535906

[16] K.-M. Ho, A. A. Shvartsburg, B. Pan, Z.-Y. Lu, C.-Z. Wang, J. G. Wacker, J. L. Fye and M. F. Jarrold, Nature, Vol. 392, 1998, pp. 582-585; http://dx.doi.org/10.1038/33369

[17] B. Liu, Z.-Y. Lu, B. Pan, C.-Z. Wang, K.-M. Ho, A. A. Shvartsburg and M. F. Jarrold, The Journal of Chemical Physics, Vol. 109, 1998, p. 9401. http://dx.doi.org/10.1063/1.477601

[18] I. Rata, A. A. Shvartsburg, M. Horoi, T. Frauenheim, K. W. M. Siu and K. A. Jackson, Physical Review Letters, Vol. 85, 2000, pp. 546-549. http://dx.doi.org/10.1103/PhysRevLett.85.546

[19] B.-X. Li, P.-L. Cao and S.-C. Zhan, Physics Letters A, Vol. 316, 2003, pp. 252-260. http://dx.doi.org/10.1016/S0375-9601(03)01173-3

[20] O. Guillois, N. Herlin-Boime, C. Reynaud, G. Ledoux, F. Huisken, Journal of Applied Physics, Vol. 95, 2004, p. 3677. http://dx.doi.org/10.1063/1.1652245

[21] M. Aceves-Mijares, A. A. González-Fernández, R. LópezEstopier, A. Luna-López, D. Berman-Mendoza, A. Morales, C. Falcony, C. Domínguez and R. Murphy-Arteaga, Journal of Nanomaterials, Vol. 2012, 2012, Article ID: 890701. http://dx.doi.org/10.1155/2012/890701

[22] Al. L. Efros and A. L. Efros, Soviet Physics: Semiconductors, Vol. 16, 1982, p 1209.

[23] S. V. Gaponenko, "Optical Properties of Semiconductor Nanocrystals," Cambridge University Press, Cambridge, 1998.

[24] L. E. Brus, The Journal of Chemical Physics, Vol. 80, 1984, p. 4403. http://dx.doi.org/10.1063/1.447218

[25] Y. Kayanuma, Physical Review B, Vol. 38, 1988, pp. 9797-9805. http://dx.doi.org/10.1103/PhysRevB.38.9797

[26] L. Dal Negro, M. Cazzanelli, L. Pavesi, S. Ossicini, D. Pacifici, G. Franzò, F. Priolo and F. Iacona, Applied 
Physics Letters, Vol. 82, 2003, pp. 4636-4638. http://dx.doi.org/10.1063/1.1586779

[27] A. Meldrum, R. F. Haglund Jr., L. A. Boatner and C. W. White, Advanced Materials, Vol. 13, 2001, pp. 1431-1444. http://dx.doi.org/10.1002/1521-4095(200110)13:19<1431 $\because$ AID-ADMA1431>3.0.CO;2-Z

[28] M. H. Nayfeh, S. Rao, N. Barry, J. Therrien, G. Belomoin, A. Smith and S. Chaieb, Applied Physics Letters, Vol. 80, 2002, pp. 121-123. http://dx.doi.org/10.1063/1.1428622

[29] M. Zacharias, J. Heitmann, R. Scholz, U. Kahler, M. Schmidt and J. Bläsing, Applied Physics Letters, Vol. 80, 2002, pp. 661-663. http://dx.doi.org/10.1063/1.1433906

[30] J. Wang, X. F. Wang, Q. Li, A. Hryciw and A. Meldrum, Philosophical Magazine, Vol. 87, 2007, pp. 11-27. http://dx.doi.org/10.1080/14786430600863047

[31] C. Delerue, G. Allan and M. Lannoo, Journal of Luminescence, Vol. 80, 1998, pp. 65-73. http://dx.doi.org/10.1016/S0022-2313(98)00071-4

[32] V. A. Belyakov, V. A. Burdov, R. Lockwood and A. Meldrum, Advances in Optical Technologies, Vol. 2008, 2008, Article ID: 279502. http://dx.doi.org/10.1155/2008/279502

[33] J. A. Luna-López, G. García-Salgado, T. Díaz-Becerril, J. Carrillo López, D. E. Vázquez-Valerdi, H. Juárez-Santiesteban, E. Rosendo-Andrés and A. Coyopol, Materials Science and Engineering B, Vol. 174, 2010, pp. 88-92. http://dx.doi.org/10.1016/j.mseb.2010.05.005

[34] E. C. Honea, A. Ogura, C. A. Murray, K. Raghavachari, W. O. Sprenger, M. F. Jarrold and W. L. Brown, Nature, Vol. 366, 1993, pp. 42-44. http://dx.doi.org/10.1038/366042a0

[35] X. L. Zhu, X. C. Zeng, Y. A. Lei, and B. Pan, The Journal of Chemical Physics, Vol. 120, 2004, p. 8985. http://dx.doi.org/10.1063/1.1690755

[36] X. L. Zhu and X. C. Zeng, The Journal of Chemical Physics, Vol. 118, 2003, p. 3558. http://dx.doi.org/10.1063/1.1535906

[37] I. H. Lee, K. J. Chang and Y. H. Lee, Journal of Physics: Condensed Matter, Vol. 6, 1994, p. 741. http://dx.doi.org/10.1088/0953-8984/6/3/014

[38] K. M. Ho, A. A. Shvartsburg, B. Pan, Z. Y. Lu, C. Z.
Wang, J. G. Wacker, J. L. Fye and M. F. Jarrold, Nature, Vol. 392, 1998, p. 582.

http://dx.doi.org/10.1038/33369

[39] A. Sieck, D. Porezag, Th. Frauenheim, M. R. Pederson and K. Jackson, Physical Review A, Vol. 56, 1997, pp. 4890-4898.

http://dx.doi.org/10.1103/PhysRevA.56.4890

[40] I. Vasiliev, S. Ogut and J. R. Chelikowsky, Physical Review Letters, Vol. 78, 1997, pp. 4805-4808. http://dx.doi.org/10.1103/PhysRevLett.78.4805

[41] D. J. Wales, Physical Review A, Vol. 49, 1994, pp. $2195-$ 2198. http://dx.doi.org/10.1103/PhysRevA.49.2195

[42] C. M. Rohlfing and K. Raghavachari, Chemical Physics Letters, Vol. 167, 1990, p. 559. http://dx.doi.org/10.1016/0009-2614(90)85469-S

[43] C. M. Rohlfing and K. Raghavachari, The Journal of Chemical Physics, Vol. 96, 1992, p. 2114. http://dx.doi.org/10.1063/1.462062

[44] H. Jahn and E. Teller, Proceedings of the Royal Society of London Series A, Mathematical and Physical Sciences (1934-1990), Vol. 161, 1937, pp. 220-235. http://dx.doi.org/10.1098/rspa.1937.0142

[45] B.-L. Gu, Z.-Q. Li and J.-L. Zhu, Journal of Physics: Condensed Matter, Vol. 5, 1993, p. 5255. http://dx.doi.org/10.1088/0953-8984/5/30/005

[46] J. C. Grossman and L. Mitas, Physical Review Letters, Vol. 74, 1995, pp. 1323-1326. http://dx.doi.org/10.1103/PhysRevLett.74.1323

[47] B. X. Li, P. L. Cao and M. Jiang, Physica Status Solidi B, Vol. 218, 2000, pp. 399-400. http://dx.doi.org/10.1002/1521-3951(200004)218:2<399:: AID-PSSB399>3.0.CO;2-R

[48] B. X. Li and P. L. Cao, Physical Review A, Vol. 62, 2000, Article ID: 023201. http://dx.doi.org/10.1103/PhysRevA.62.023201

[49] B. X. Li and P. L. Cao, Journal of Physics: Condensed Matter, Vol. 13, 2001, p. 1. http://dx.doi.org/10.1088/0953-8984/13/1/301

[50] H. Haberland, "Clusters of Atoms and Molecules: Theory, Experiment, and Clusters of Atoms," Springer, New York, 1994. 